\title{
Sensitivity Analysis of Material Microstructure Effects on Predicted Crack Paths using Finite Element Simulations
}

\author{
Anaïs Jacob $^{1}$ and Ali Mehmanparast ${ }^{1 *}$ \\ ${ }^{1}$ Offshore Renewable Energy Centre, School of Energy, Environment and Agrifood, Cranfield \\ University, Cranfield Bedfordshire MK43 0AL, UK. \\ *Corresponding author: a.mehmanparast@cranfield.ac.uk
}

\begin{abstract}
The effects of microstructure, grain and grain boundary properties on predicted damage paths and indicative crack propagation direction have been examined for a polycrystalline material using mesoscale finite element simulations. Numerical analyses were carried out on a compact tension specimen geometry containing granular mesh structures with random grain shapes and sizes of average diameter $100 \mu \mathrm{m}$. Nano-indentation tests were performed to investigate the dependency of mesoscale hardness measurements on the indentation location with respect to grain and grain boundary regions. Finite element results have shown that under tensile loading conditions, the predicted damage paths are very sensitive to the granular mesh structure, grain boundary properties and individual grain properties. Furthermore, finite element results have revealed that the cracking mode (i.e. transgranular/intergranular) and maximum crack deviation angle are strongly dependent on the material microstructures employed in simulations.
\end{abstract}

Keywords: damage path, crack path, mesoscale finite element modelling, granular mesh structure, microstructure, polycrystalline material.

\section{Introduction}

Material degradation occurs in engineering components operating under different loading conditions at various temperatures and subsequently can lead to crack formation. It is known that the presence of cracks in components and structures may significantly reduce their remaining lifetimes. In order to assess the structural integrity of engineering components, crack initiation and growth tests are often performed on laboratory scale specimens to characterise the crack propagation behaviour of a material under various loading conditions (e.g. static or dynamic) replicating the actual loading conditions applied on a component during operation. The results from these experiments can be alternatively employed in life assessment procedures to predict the remaining life of the examined components. Although performing experiments provides data from which the crack initiation and growth behaviour can be characterised, testing is usually expensive and time consuming; for instance, a long term creep crack growth test on a fracture mechanics specimen geometry may take up to a couple of years to complete. Hence, finite element (FE) simulations are commonly used to 
predict the crack growth behaviour of engineering materials in much shorter timescales and at significantly lower cost.

Various FE approaches have previously been used by researchers to predict the crack initiation and growth behaviour of the material of interest under creep, fatigue and fracture loading conditions. For example, the creep crack initiation and growth behaviour of Type $316 \mathrm{H}$ stainless steel at $550{ }^{\circ} \mathrm{C}$ has been predicted by $\mathrm{FE}$ simulations in [1] and [2]. A similar FE approach has been used in [3] to predict the fracture toughness of EN31 steel by running simulations on a compact tension, $\mathrm{C}(\mathrm{T})$, specimen geometry in which cohesive elements were used to simulate crack propagation under severely high tensile loading conditions. This approach has also been implemented in [4] and [5]. Finite element simulations have also been used in [6] as well as in [7] to predict the fatigue crack growth of a material subjected to cyclic loading conditions using a damage accumulation and growth simulation approach. An FE technique, which is widely used to simulate crack propagation in metallic materials, is the eXtended Finite Element Method (XFEM). Indeed, this method has been implemented in order to allow the modelling of random discontinuities and non-smooth features [8], [9] and [10]. The predictions from the FE models in the literature are validated through comparisons with the existing experimental data or analytical solutions. In the majority of these works, a straight crack path is predefined in the model (e.g. along the symmetry axis for the case of $\mathrm{C}(\mathrm{T})$ specimen geometry) and the crack growth is simulated using node-release or stress reduction techniques. The main restriction of these modelling approaches is the restriction of the crack growth direction to the predefined crack path.

The majority of FE models available in the literature are capable of predicting macroscopic crack propagation paths for different metallic materials. However, to account for the cracking mode and particularly to simulate intergranular crack growth along the grain boundaries in polycrystalline materials, cohesive elements are often used in 2D and 3D mesoscale FE analyses (see e.g. [11], [12] and [13]). Another modelling approach that considers the grain structure of a polycrystalline material in crack initiation and growth simulations is the crystal plasticity finite element (CPFE) method in which crystallographic textures are accounted for in numerical analyses. It has been demonstrated in [14] and [15] that this modelling technique can be employed in mesoscale and microscopic scale simulations of damage evolution and crack growth.

Experimental observations have shown that although the crack path in polycrystalline materials is straight in the macroscale, the mesoscale crack growth behaviour can be "intergranular" under static creep loading conditions at elevated temperatures e.g. [16], [17] and [18], or "transgranular" under cyclic fatigue loading conditions at low temperatures [19] and [20]. The FE models, which are currently available in the literature, may successfully predict intergranular and transgranular crack initiation and growth under different loading conditions. However, there is no existing model that is capable of predicting combined intergranular-transgranular crack growth behaviour for instance under creep-fatigue loading conditions. Therefore, a granular mesh structure generated based on the actual microstructure of a polycrystalline material, with the ability to differentiate between intergranular and transgranular crack growth mechanisms, has been developed and is presented in this paper. This model has been previously validated in [21] by comparing the predicted stress distribution fields ahead of the crack tip and also $K$ and $J$ fracture mechanics parameters predicted by FE with those obtained from analytical solutions. Moreover, a similar granular mesh structure has also been used in [22] and [23] to predict the development of intergranular surface cracks using a combined oxidation-creep damage model. 
In this work, different granular mesh structures, with effectively the same average grain size, have been generated and integrated into the crack tip region of a $\mathrm{C}(\mathrm{T})$ specimen to investigate the dependency of damage/crack paths on material microstructure, grain properties and grain boundary (GB) properties. In this paper, the variation of GB properties are first explained and then the procedure to develop granular mesh structures in addition to the material property scenarios considered for grain and GB regions are explained. The FE results from this study have been discussed in terms of the sensitivity of the damage paths to the material microstructure and local properties. The focus of this study is exclusively on the sensitivity analysis of damage paths, therefore no crack growth predictions under a specific loading condition are presented in the paper.

\section{Material Property Variations in Polycrystals}

The polycrystalline material examined in this study is Type $316 \mathrm{H}$ austenitic stainless steel, which is widely used in the UK power industry. The mechanical response, fracture toughness, fatigue crack growth and creep crack growth behaviour of the material used in this study has been previously characterised in [24], [25] and [26]. The tensile response of the as-received $316 \mathrm{H}$ material at $550{ }^{\circ} \mathrm{C}$, which is the typical operating temperature of power plant components made of $316 \mathrm{H}$, has been taken from [24] and are presented in Figure 1. Note that the tensile curves shown in Figure 1 represent the global tensile behaviour of the material under tensile loading conditions and provides an average measure of deformation for a large number of grains available in the gauge region of the tensile round bar specimen.

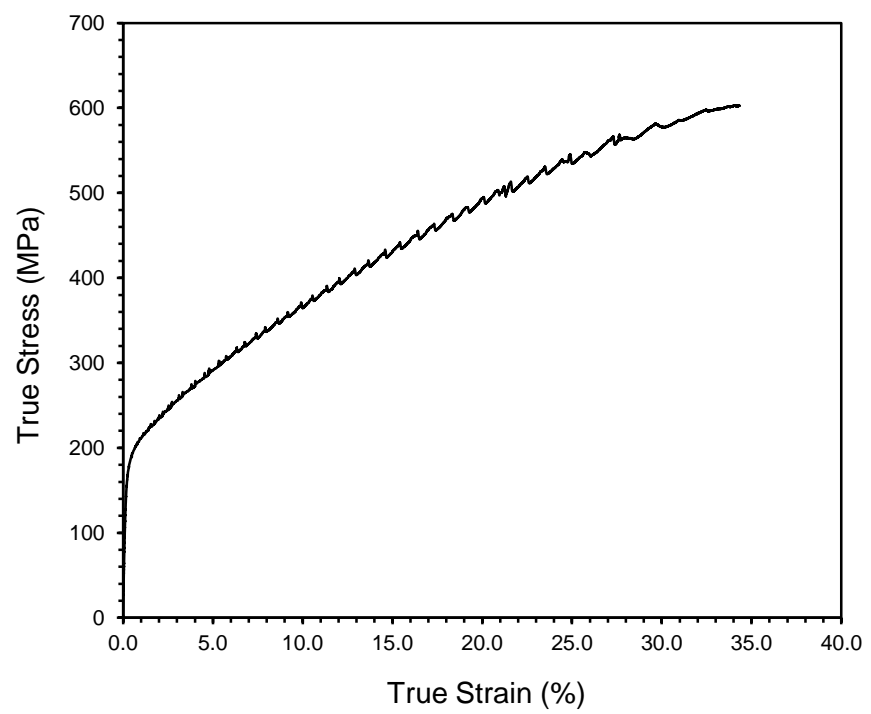

Figure 1: Tensile behaviour of $316 \mathrm{H}$ stainless steel at $550{ }^{\circ} \mathrm{C}[24]$.

\subsection{Variation of Mechanical Behaviour in Different Grains}

The microstructural morphology of the as-received $316 \mathrm{H}$ material has previously been characterised by performing electron backscatter diffraction (EBSD) tests in [27]. An example of an EBSD map obtained for 316H material has been taken from [27] and is shown in Figure 2. Each colour in the EBSD pattern represents a crystallographic orientation and it can be seen in Figure 2 that there is no texture observed in the as-received $316 \mathrm{H}$ material and the grain orientations are, to some extent, randomly distributed. 


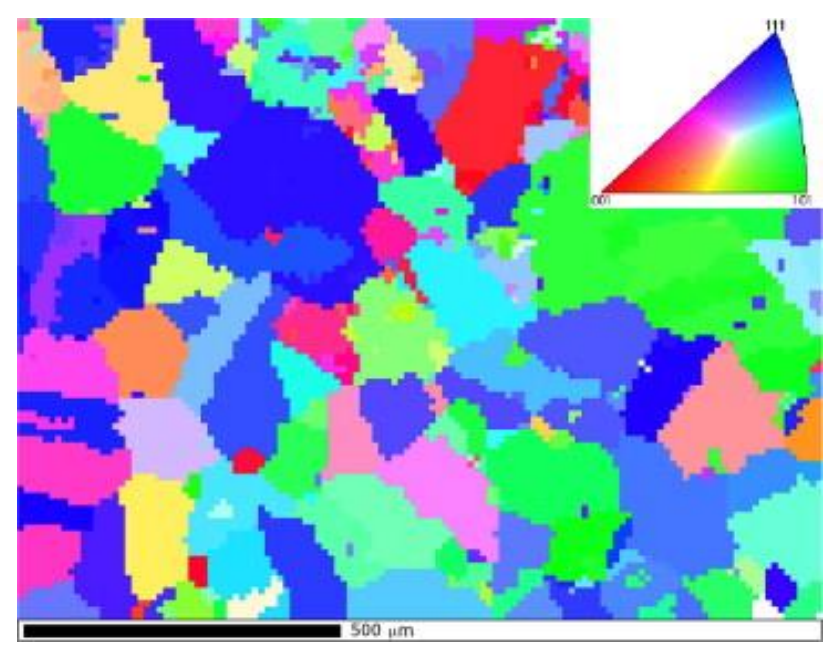

Figure 2: An example of EBSD map for 316H stainless steel [27].

Other studies have previously been conducted to examine the influence of crystallographic orientations on the mesoscale mechanical responses of different families of grains for $316 \mathrm{H}$ stainless steel material. The elastic diffraction constants for different crystallographic planes in Type $316 \mathrm{H}$ stainless steel as-received material were quantified by performing in-situ Neutron Diffraction (ND) measurements on uniaxial tensile specimens in [28] and [29]. The ND measurement results from these tests have revealed that although similar elastic diffraction constants were obtained in the local coordinate, the stiffness values change when the global stress is plotted against micro strains measured for different crystallographic planes. This implies that the global deformation behaviour of this polycrystalline material can be dependent on the grain orientations.

In addition to the crystallographic orientations, which subsequently influence the mesoscale mechanical response of different grains, it is evident from the Hall-Petch equation that the yield stress $\sigma_{y}$ (hence hardness) of the material is dependent on the grain diameter, $D$ (see Eqn 1). This means that in a polycrystalline material, such as the as-received Type $316 \mathrm{H} \mathrm{SS}$, even for the grains with the same crystallographic orientation, the mechanical response can be different, depending on the individual grain size.

$$
\sigma_{y}=\sigma_{0}+\frac{k}{\sqrt{D}}
$$

It has been shown in [30] that the effective grain size in a polycrystalline material may influence the mechanism of yielding or failure. Moreover, it has been shown in [31] that the fatigue crack growth behaviour of the material is sensitive to the material grain size.

\subsection{Nano-indentation Tests}

In order to further examine the variation of material properties in different grains, nanoindentation tests have been performed in this work on ground, polished and etched $316 \mathrm{H}$ samples (specimens 1 and 2) extracted from an ex-service steam header supplied by EDF Energy. Nano-indentation tests were performed along vertical-horizontal arrays and the hardness measurement results are shown in Figure 3 and Figure 4. As seen in Figure 3(a) and Figure 4(a) nano-indentation tests were performed at different locations with respect to grains and grain boundaries (GBs) to examine the sensitivity of nano-hardness results to material microstructure and indentation location. It can be seen in Figure 3(b) and Figure 4(b) that in each of the grains examined some level of scatter was observed in the nano-hardness results. 
However, it is evident from the nano-indentation results that the average nano-hardness values in smaller grains are higher than in larger grains. This observation is consistent with the HallPetch equation. Finally seen in Figure 3 and Figure 4 is that when the indentation points hit the GBs or a triple junction, a relatively higher hardness value, which is greater than individual averaged nano-hardness values measured in each of the neighbouring grains, was obtained from the indentation tests. This may be associated with lower dislocation density, hence higher hardness values, close to the GB regions.

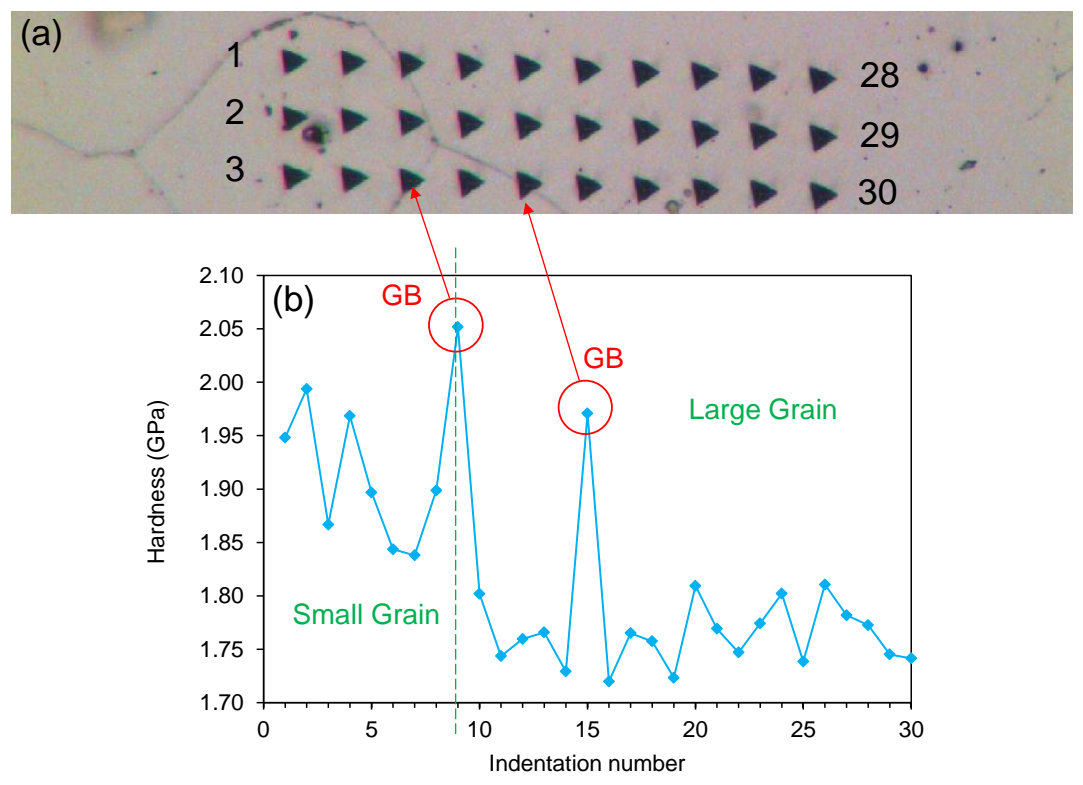

Figure 3: (a) Demonstration of nano-indentation locations with respect to grains and grain boundaries (b) Nano-indentation test results, on $316 \mathrm{H}$ specimen 1

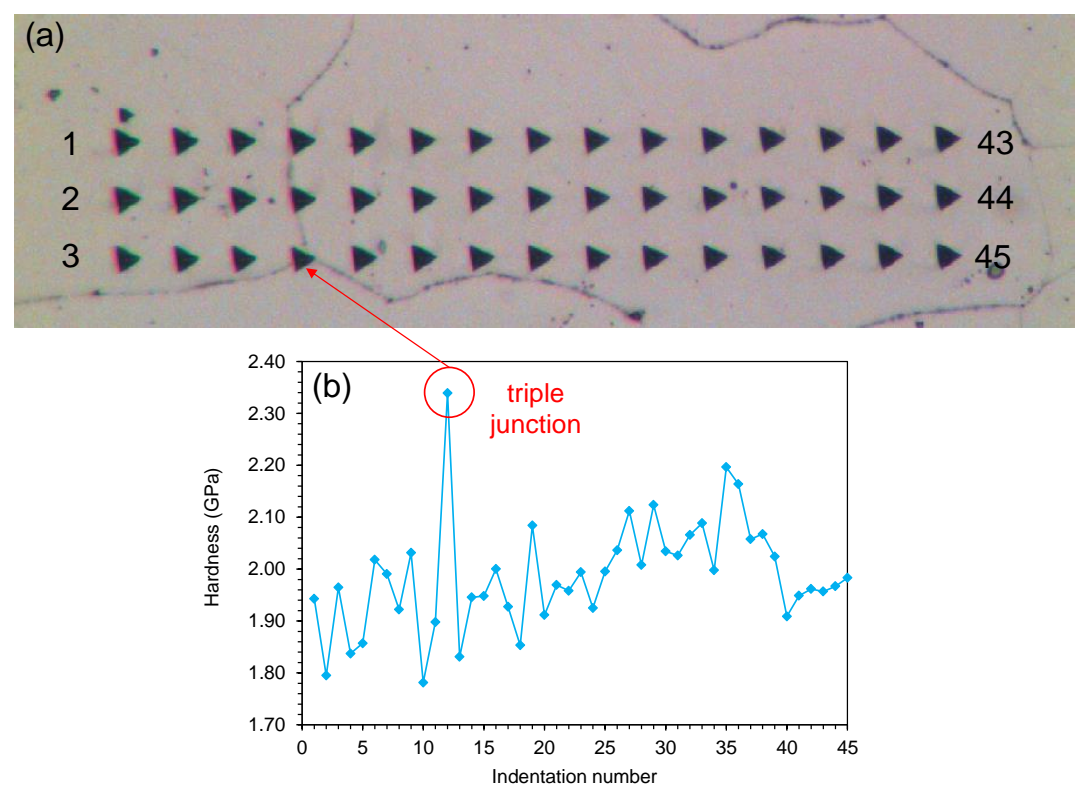

Figure 4: (a) Demonstration of nano-indentation locations with respect to grains and grain boundaries (b) Nano-indentation test results, on $316 \mathrm{H}$ specimen 2 


\section{Finite Element Model}

The experimental nano-hardness results in Section 2 showed that the mesoscale mechanical properties of the material depend on the grain size and the indentation location with respect to the grain and GB regions. Furthermore, it was shown and discussed how the microscopic tensile behaviour of the material is severely sensitive to the grain specific crystallographic plane. This means that even two grains of the same size may have different mechanical responses, depending on their crystallographic orientations. The observations shown above indicate that in order to perform realistic mesoscale crack growth simulations for a polycrystalline material, various mechanical properties need to be assigned to different grains. In addition, although the GBs do not physically exist in the material microstructure (GBs are in fact interface regions between different grains) they need to be modelled in FE simulations in order to enable the FE model to distinguish between intergranular and transgranular crack growth mechanisms (which may occur for instance in creep-fatigue interaction tests). Therefore, granular mesh structures consisting of hundreds of grains and GBs have been generated in this work to investigate the dependency of damage paths on material microstructure and mechanical property variations in different grains and GBs. The procedure to develop the granular mesh structures in FE simulations has been set out in this section and different scenarios considered to define material properties for grain and GBs are explained.

\subsection{Granular Mesh Structure}

To replicate the granular microstructure of Type 316H SS [32], a two-dimensional (2D) granular unit cell consisting of randomly shaped grains of average diameter $100 \mu \mathrm{m}$, with the grain size variation ranging from 50 to $150 \mu \mathrm{m}$, and GBs with a width of $1 \mu \mathrm{m}$, was generated using the Voronoi tessellation technique [33] (see Figure 5). This granular unit cell was imported into the FE software package ABAQUS and integrated onto the Chevron notch tip region of a standard $\mathrm{C}(\mathrm{T})$, fracture mechanics specimen geometry of width $W=50 \mathrm{~mm}$, height $H=60 \mathrm{~mm}$ and initial crack length $a_{0}=25 \mathrm{~mm}$.

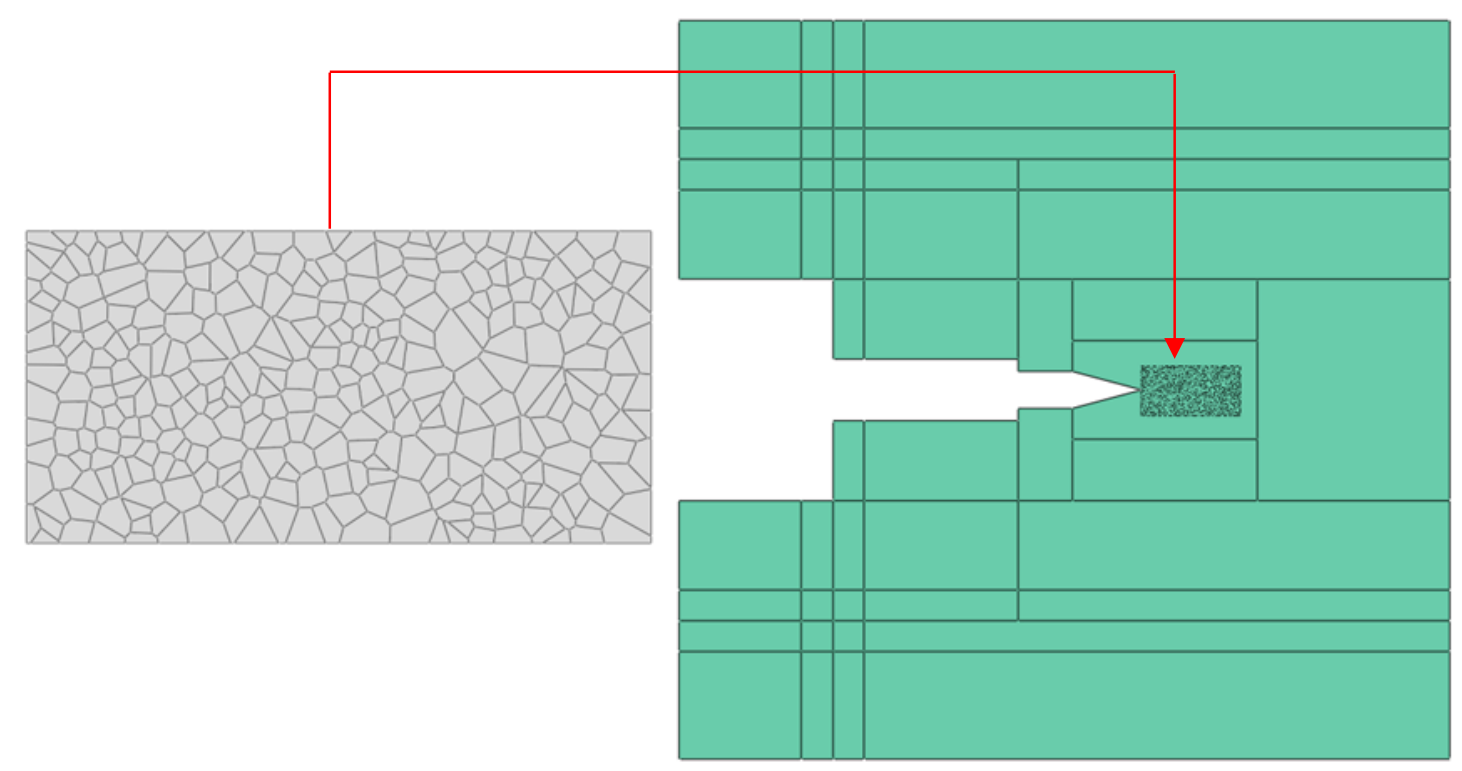

Figure 5: Granular unit cell integrated onto compact tension specimen geometry 
In order to assess the influence of random grain structures, with the same average grain diameter, on the crack initiation and growth behaviour of Type $316 \mathrm{H}$ polycrystalline material, the generated unit cell shown in Figure 5 was rotated anticlockwise by $90^{\circ}, 180^{\circ}$ and $270^{\circ}$ (see Figure 6) and then integrated onto the $\mathrm{C}(\mathrm{T})$ specimen geometry in ABAQUS. Subsequently each of the four granular geometries (containing $0^{\circ}, 90^{\circ}, 180^{\circ}$ and $270^{\circ}$ rotated unit cells) was meshed in ABAQUS/Standard using plane stress quadrilateral CPS4R elements. An example of a $\mathrm{C}(\mathrm{T})$ specimen with a granular mesh structure located at the crack tip region is shown in Figure 7. Elastic-plastic simulations were performed by pulling the $\mathrm{C}(\mathrm{T})$ geometry in tension using a vertical displacement of $0.5 \mathrm{~mm}$ in both directions (pulling the top pin $0.5 \mathrm{~mm}$ upwards and bottom pin $-0.5 \mathrm{~mm}$ downwards). The loading condition in ABAQUS was applied using a static-step and an amplitude function was used to gradually increase the applied displacement as the simulation continued. Note that due to numerical difficulties, some simulations terminated before reaching the maximum displacement defined in the model.

$0^{\circ}$ rotation

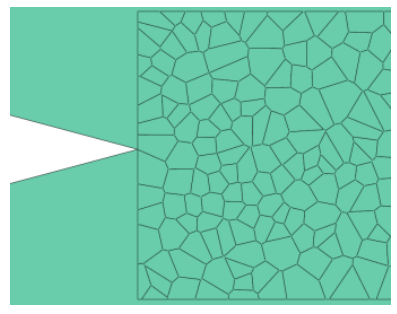

$90^{\circ}$ rotation

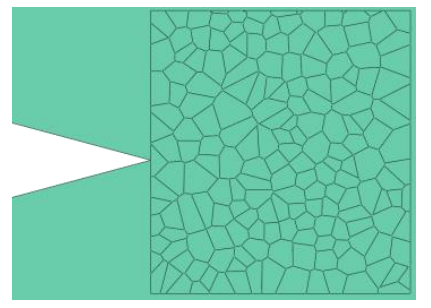

$180^{\circ}$ rotation

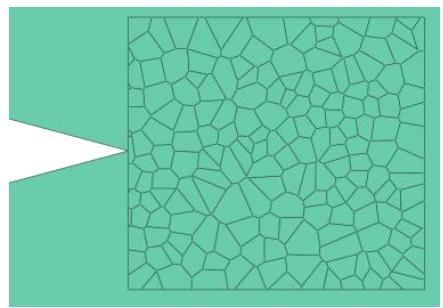

$270^{\circ}$ rotation

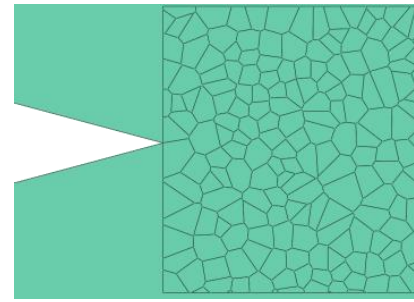

Figure 6: Rotation of the granular unit cell

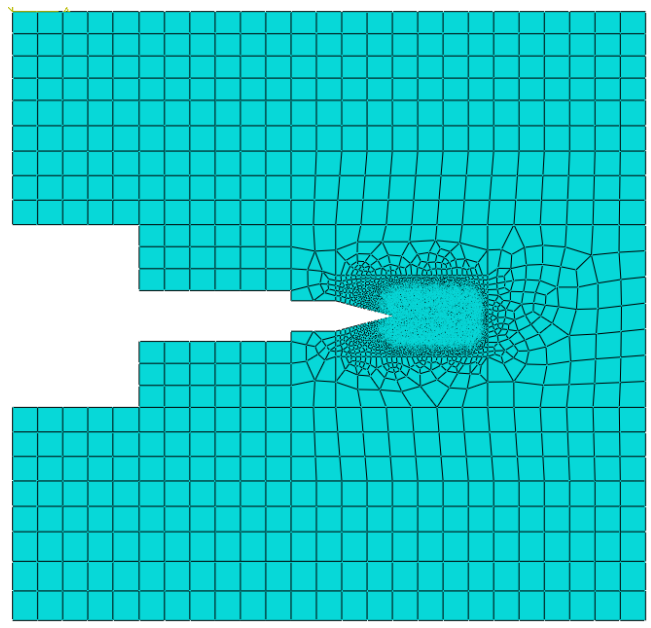

Figure 7: An example of a granular mesh structure located at the crack tip region of a $\mathrm{C}(\mathrm{T})$ specimen

\subsection{Grain and Grain Boundary Properties}

In this study, $316 \mathrm{H}$ bulk tensile properties at $550{ }^{\circ} \mathrm{C}$ (see Figure 1 and Table 1) were used as the reference properties in all FE simulations and variations in mechanical properties were made according to this reference mechanical behaviour. Three scenarios were considered to assign material properties to different grains and GBs in each of the four granular mesh structures $\left(0^{\circ}, 90^{\circ}, 180^{\circ}, 270^{\circ}\right)$ examined: 
i. $\quad$ Case 1: same elastic-plastic properties $\left(E=140 \mathrm{GPa}, v=0.3, \sigma_{y}=170 \mathrm{MPa} 550{ }^{\circ} \mathrm{C}\right)$ for all the grains and GBs.

ii. Case 2: same elastic properties $(E=140 \mathrm{GPa}, v=0.3)$ for all the grains and GBs. Reference plastic properties for all the grains $\left(\sigma_{y}=170 \mathrm{MPa}\right)$ and different but unified plastic properties for all the GBs.

iii. Case 3: same elastic properties $(E=140 \mathrm{GPa}, v=0.3)$ for all the grains and GBs. Different plastic properties, within a predefined range of scatter with respect to the reference properties, for various grains, and different but unified plastic properties for all the GBs.

In those cases where the GBs were assigned different plastic properties compared to the reference values shown in Table 1, the plastic tensile data were shifted up by factors of 1.1, $1.5,5,15$ and 50 times higher than the reference plastic data obtained from $316 \mathrm{H}$ at $550{ }^{\circ} \mathrm{C}$. Higher plastic tensile properties assumptions for GB elements were made due to the higher hardness values observed at the GBs in nano-indentation tests in Figure 3 and Figure 4. In Case 3 where different plastic properties were assigned to various grains, different scatter ranges of $\pm 3 \%, \pm 6 \%$, and $\pm 12 \%$ of the reference plastic properties $\left(\sigma_{y}=170 \mathrm{MPa}\right)$ were considered. In Case 3, 100 different plastic properties were randomly selected from the predefined scatter range and arbitrarily assigned to various grains in the granular mesh structure.

Table 1: Tensile properties of $316 \mathrm{H}$ stainless steel at $550{ }^{\circ} \mathrm{C}$

\begin{tabular}{|c|c|c|}
\hline Young's modulus, $E(\mathrm{GPa})$ & Poisson ratio, $v$ & Yield stress, $\sigma_{y}(\mathrm{MPa})$ \\
\hline 140 & 0.3 & 170 \\
\hline
\end{tabular}

\subsection{Damage Model}

Simulations were conducted using three built-in damage models available in ABAQUS/ Standard: ductile damage, shear damage and Johnson-Cook damage model. It has been explained and discussed in [34] that ductile damage is the most appropriate model for monotonic loading conditions. Therefore, in this study ductile damage was chosen as the main model to predict crack initiation and propagation paths in $\mathrm{C}(\mathrm{T})$ specimens containing granular mesh structures and subjected to monotonic loading conditions. The loading conditions (i.e. $0.5 \mathrm{~mm}$ displacement) and damage criteria were kept the same in all FE simulations to investigate the sensitivity of crack path predictions to the grain structure and local properties employed in FE simulations.

The ductile damage model mechanism is schematically shown in Figure 8. As seen in this figure, for a material under tensile loading conditions, damage initiation, which corresponds to the material state at the onset of damage, occurs when a critical value of strain is attained in an element (point $\mathrm{c}$ in Figure 8). Subsequent to damage initiation, damage evolution starts to occur which then leads to a continuous reduction in the load carrying capacity, as seen in Figure 8. As also seen in this figure, the failure in the ductile damage model is defined to occur when the element reaches a critical value of strain at which the element entirely loses its load carrying capacity (point $d$ in Figure 8). Note that the c-d curve in Figure 8 shows the material degradation during the damage evolution process, whereas the $c-d^{\prime}$ curve demonstrates the mechanical response of the undamaged material. 


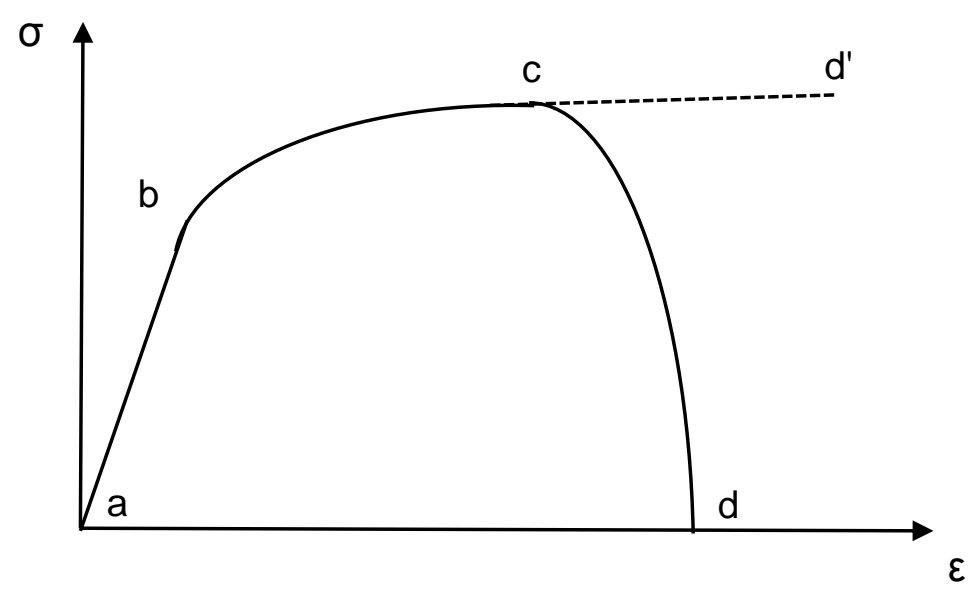

Figure 8: Schematic illustration of the ductile damage mechanism

Eqn 2 expresses the initiation criterion based on the ductile damage model [35]-[38]:

$$
D_{c}=1-\frac{\sigma_{R}}{\left(2 E y_{c}\right)^{\frac{1}{2}}}
$$

where $D_{c}$ is the critical value of damage at macrocrack initiation/failure, $\sigma_{R}$ is the critical value of the stress tensor $\sigma$ for the rupture condition and $y_{c}$ is the critical value of the damage strain energy release rate. The damage evolution criterion based on the ductile damage model can be defined as [35]-[38]:

$$
D=D_{c}\left(\frac{p\left[\frac{2}{3}(1+v)+3(1-2 v)\left(\frac{\sigma_{H}}{\sigma_{e q}}\right)^{2}\right]-\epsilon_{D}}{\epsilon_{R}-\epsilon_{D}}\right)
$$

where $\mathrm{p}$ is the accumulated plastic strain, $\sigma_{e q}$ is the Von-Mises equivalent stress, $\sigma_{H}$ is the hydrostatic stress, $\epsilon_{R}$ is the strain at failure and $\epsilon_{D}$ is the strain at the damage threshold.

\section{Damage Paths Prediction Results}

The damage paths predictions obtained from FE simulations have been presented in this section. For each of the material property scenarios considered (see Section 3.2), the predicted damage path observations have been described and briefly discussed. In addition to damage path predictions, the corresponding strain distribution fields ahead of the crack tip have also been presented for each set of FE simulations considered in this study. Note that due to the large number of elements and complicated geometry employed in FE analyses, the simulations terminated at different step times (hence load levels) under monotonic loading conditions. Moreover, in some FE simulations the ductile damage parameter did not reach the critical value of unity, and hence did not fully damage, at the time of termination. Therefore, although the damage path predictions obtained from these simulations provide indicative crack paths predictions, the lengths of the damage path regions were not directly comparable and the study was focused on the sensitivity of "indicative crack paths" to the material microstructures and grain/GB properties. 


\subsection{Case 1 Material Properties Scenario}

As explained in Section 3.2, in the first material properties scenario the same elastic and plastic properties (see Table 1 and Figure 1) were assigned to all the grains and GBs. This means that the material was considered to be completely homogeneous in Case 1 . The damage path predictions for different granular mesh structures (with granular unit cell rotation angles of $0^{\circ}, 90^{\circ}, 180^{\circ}$ and $270^{\circ}$ ) have been presented in Figure 9. Note that in all the FE contour plots presented in this paper, the maximum damage value, which is obtained at the end of simulation (i.e. when the FE simulation was terminated), is shown in red whereas the minimum damage value is shown in blue. It must also be noted that since different simulations were terminated at various step times, and hence the specimen reached different load levels at the end of each simulation, the maximum damage values differ from one simulation to another.

It can be seen in Figure 9(a) that in the simulation with the original granular mesh structure (with $0^{\circ}$ rotation angle) the damage path was initiated at the GB located at the Chevron notch tip and continued to develop along the specimen symmetry line (i.e. the centre line at the mid height of $\mathrm{C}(\mathrm{T})$ specimen). In order to examine the dependency of the predicted damage path on the load level, the simulation was repeated on the same granular mesh structure with a lower applied load and the result is shown in Figure 9(b). Comparing the predicted damage paths in Figure 9(a) and (b) it can be seen that for the examined mesh structure, the indicative crack path remained unchanged by decreasing the load level. To investigate the sensitivity of the predicted damage paths to the material microstructure, simulations were performed on granular mesh structures with $90^{\circ}, 180^{\circ}$ and $270^{\circ}$ granular unit cell rotation angles and the results are shown in Figure 9(c), (d) and (e), respectively. It can be seen in Figure 9 that the damage paths in simulations with $90^{\circ}$ and $180^{\circ}$ unit cell rotation were relatively straight (hence transgranular) with no noticeable deviation from the centre line, similar to that observed in Figure 9(a). However, Figure 9(e) shows that when the unit cell was rotated by $270^{\circ}$, a different damage path with the deviation angle of $9^{\circ}$ from the specimen centre line was predicted. Further seen in Figure 9(e) is that the indicative crack path in this simulation was initiated at the GB located at the Chevron notch tip, and continued to follow the same direction throughout the granular mesh structure. To examine the mesh dependency of the deviated damage path in Figure 9(e), this granular structure was re-meshed using finer quadrilateral elements and the results are shown in Figure 9(f). The same indicative crack growth directions were found in Figure 9(e) and (f) indicating that the predicted damage path for this rotated granular unit cell was insensitive to the mesh size.

The plastic strain distributions along the loading direction (PE22 or $\varepsilon_{y}$ ) predicted for different granular mesh structures are presented in Figure 10. Note that in Figure 10 the plastic strain values of close to zero and above $0.2 \%$ are shown in blue and red contours, respectively. Comparing Figure 10 to the damage path predictions in Figure 9, it can be seen that for the deviated damage paths predicted in Figure 9(e) and (f), the corresponding plastic strain fields are non-symmetric (see Figure 10(e) and (f)) whereas symmetric plastic distribution fields have been observed in other cases with straight damage paths. 
(a) $0^{\circ}$ Granular unit cell rotation

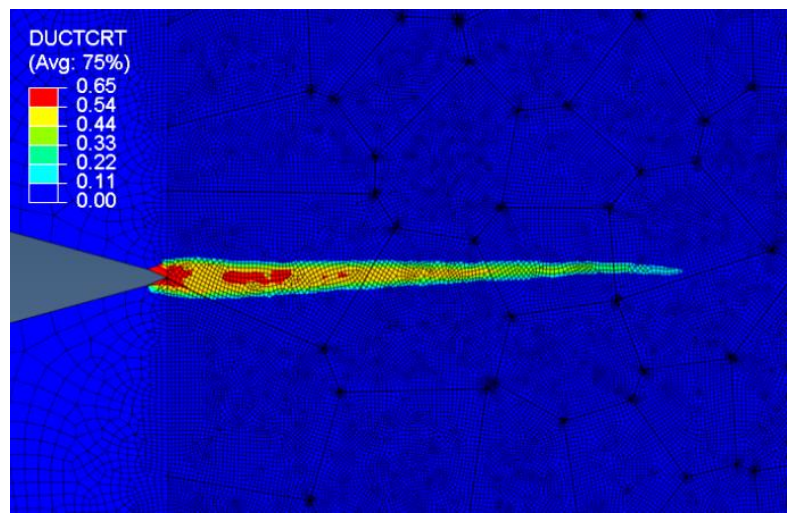

(d) $180^{\circ}$ Granular unit cell rotation

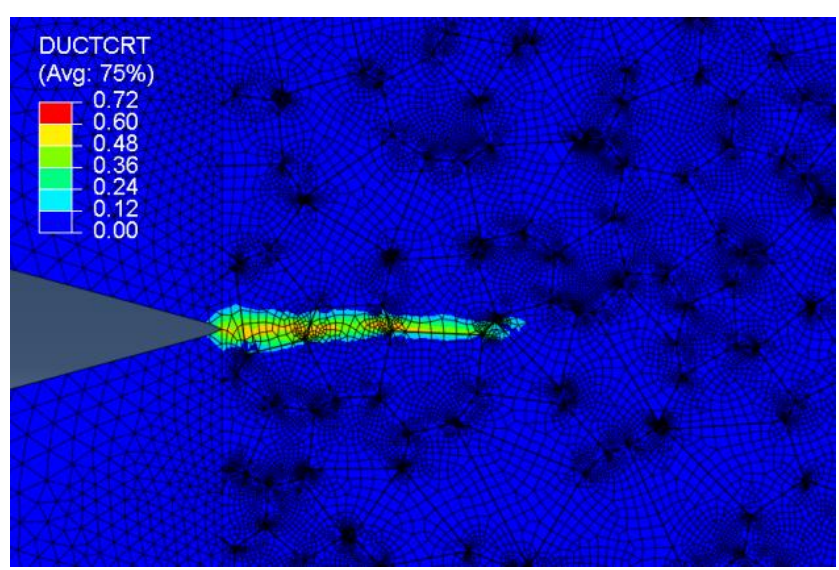

(b) $0^{\circ}$ Granular unit cell rotation and a lower load

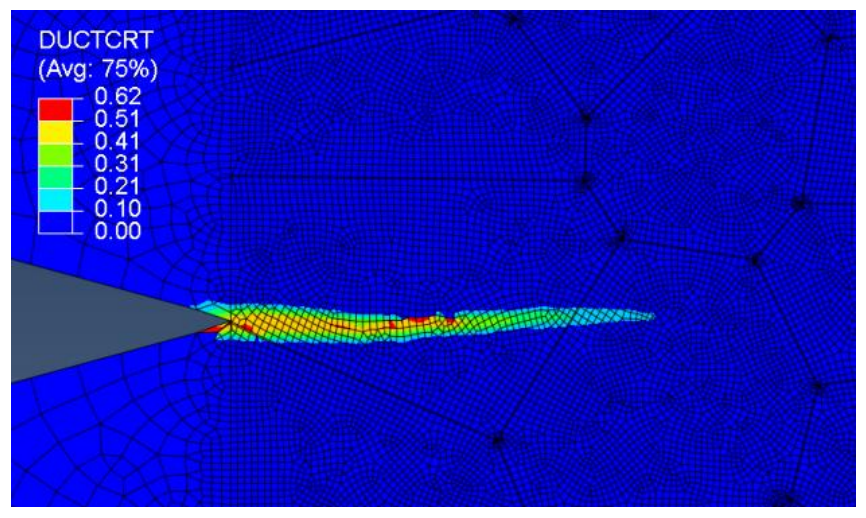

(e) $270^{\circ}$ Granular unit cell rotation

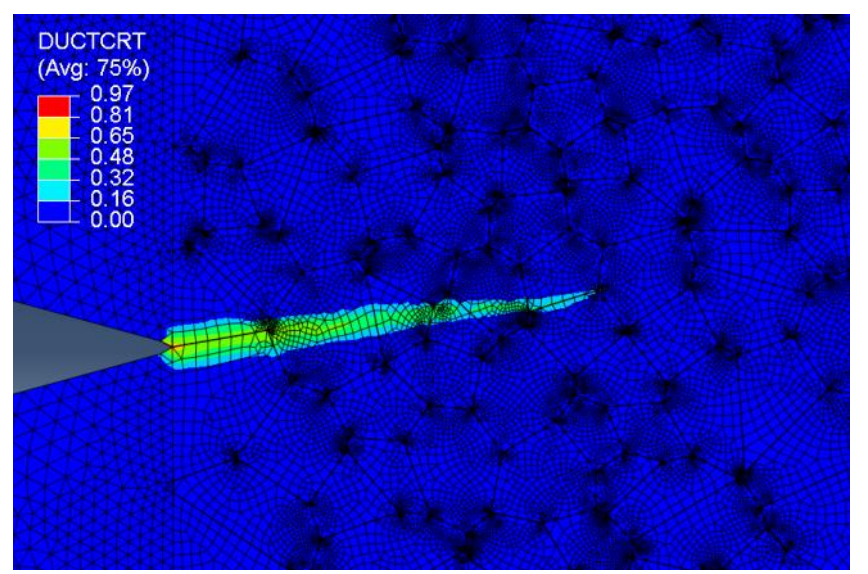

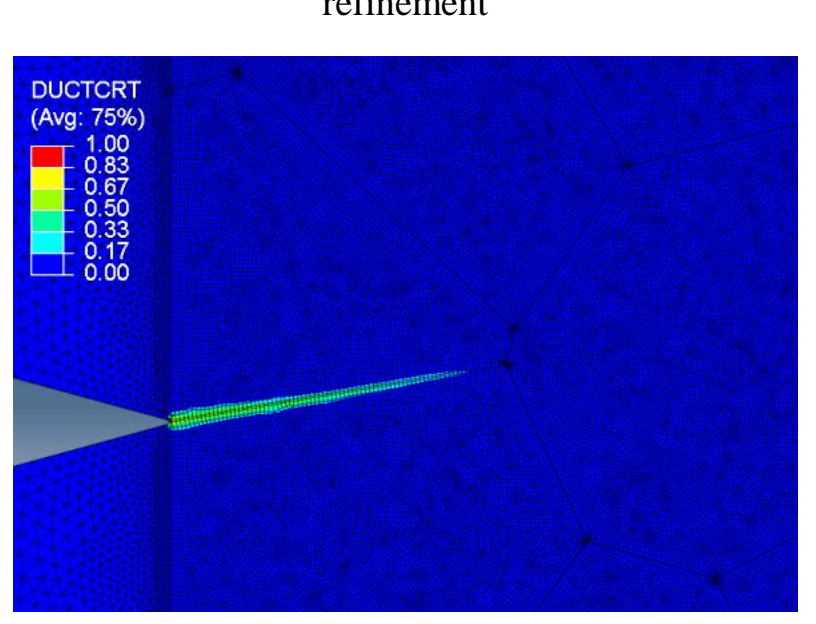

(c) $90^{\circ}$ Granular unit cell rotation

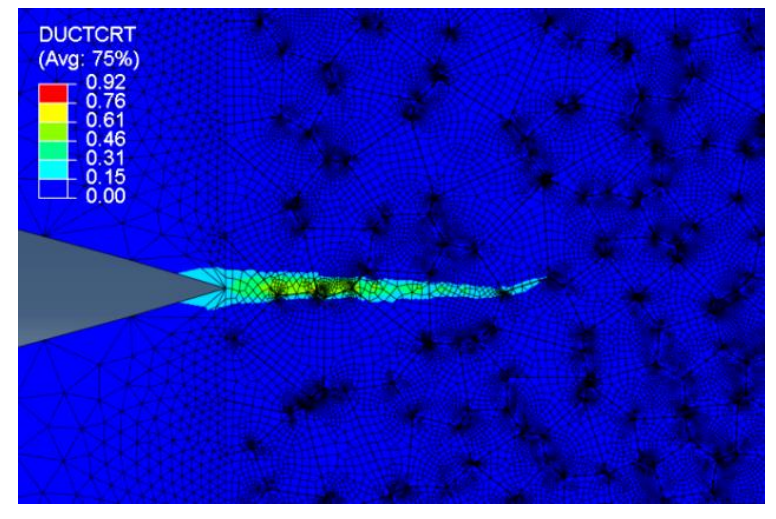

(f) $270^{\circ}$ Granular unit cell rotation and mesh refinement

Figure 9: Damage path predictions for Case 1 material properties scenario 
(a) $0^{\circ}$ Granular unit cell rotation

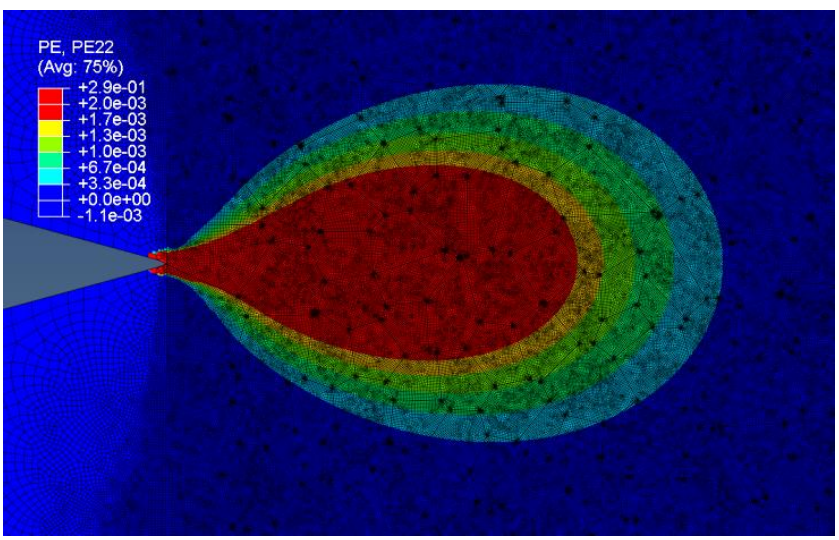

(d) $180^{\circ}$ Granular unit cell rotation

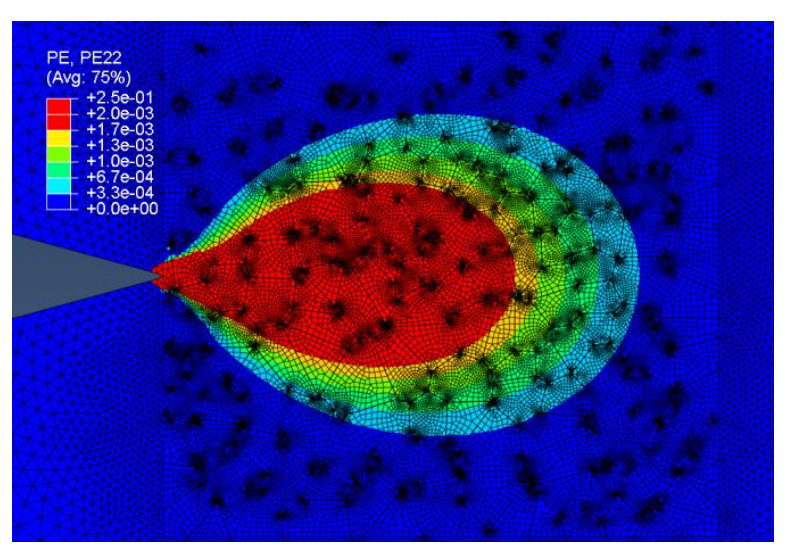

(b) $0^{\circ}$ Granular unit cell rotation and a lower load

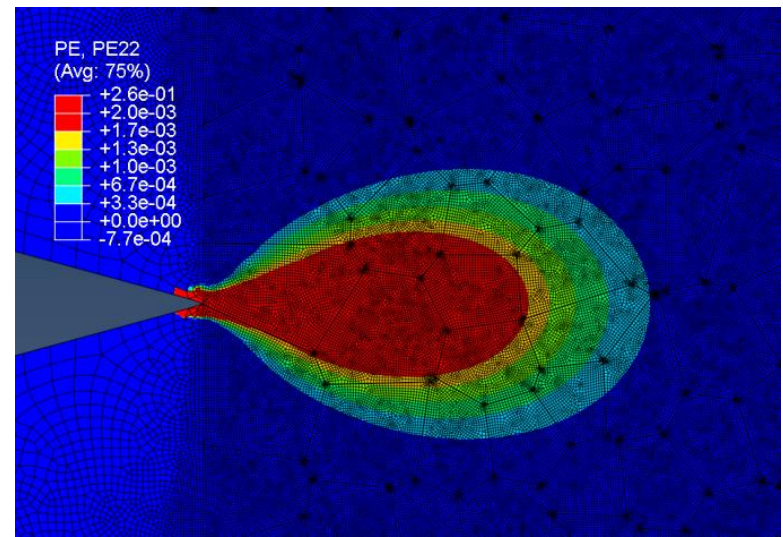

(e) $270^{\circ}$ Granular unit cell rotation

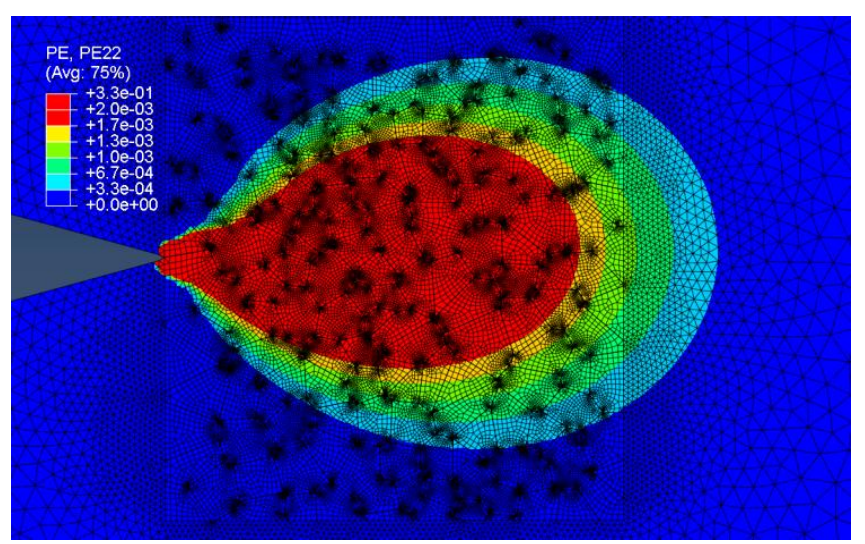

(c) $90^{\circ}$ Granular unit cell rotation

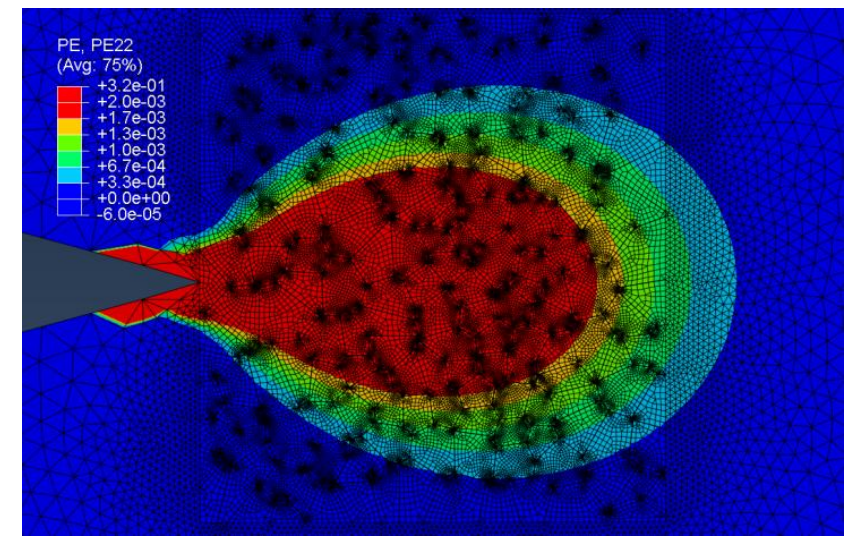

(f) $270^{\circ}$ Granular unit cell rotation and remesh

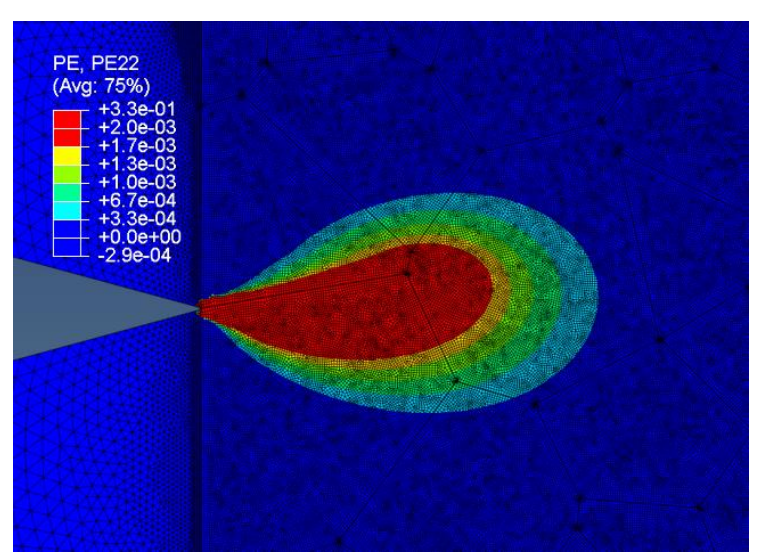

Figure 10: Plastic strain distribution fields predicted for Case 1 material properties scenario 


\subsection{Case 2 Material Properties Scenario}

As explained in Section 3.2, in the Case 2 material properties scenario, the same elastic properties were assigned to the grain and GB regions. Moreover, reference plastic properties were assigned to the grains (see Figure 1 and Table 1), whereas the plastic properties for GBs were increased by factors of 1.1, 1.5, 5, 15 and 50 times higher than the reference plastic data obtained from $316 \mathrm{H}$ at $550{ }^{\circ} \mathrm{C}$. The damage path predictions from these simulations are presented in Figure 11 and Figure 12 for the granular mesh structures containing $0^{\circ}$ and $90^{\circ}$ rotated unit cells, respectively. It can be seen in Figure 11 that by increasing the yield stress of the GB elements to 15 times higher than the bulk material, the damage path for the given granular mesh structure (with $0^{\circ}$ unit cell rotation) remains unchanged and the indicative crack path falls along the specimen symmetry line. However, it can be seen in Figure 11(e) that when the GB plastic properties were increased to 50 times higher than the bulk properties, in addition to a straight damage path ahead of the crack tip, another three damage branches were also predicted. It can also be observed in Figure 11(e) that one of the thinner damage path branches initiated at the GB located at the crack tip and developed downwards with a deviation angle of $25^{\circ}$ (possible indicative of crack bifurcation) whereas the other two fell above and below the symmetry line. The deviation angle for these two disjointed damage paths is found close to $0^{\circ}$ with respect to the specimen centre line $\left(90^{\circ}\right.$ to the loading direction).

The FE prediction results for the granular mesh with a $90^{\circ}$ rotated unit cell in Figure 12 show that, similarly to the first granular mesh in Figure 11, the damage path was found to be insensitive to the change in the plastic properties of the GB regions when the yield stress was increased up to 5 times higher than the bulk properties. However, when the yield stress for the GB elements was increased by factors of 15 and 50 times higher than the bulk properties, a shorter straight damage path linked up with the pre-existing Chevron notch and longer disjointed damage paths were predicted ahead of the notch tip. The plastic strain distribution fields for these simulations are shown in Figure 13. It can be seen in this figure that the global strain fields ahead of the crack tip are insensitive to a change in GB properties as long as uniform properties are assigned to all the grains in the mesh structure. 
(a) 1.1 times higher plastic properties in GB

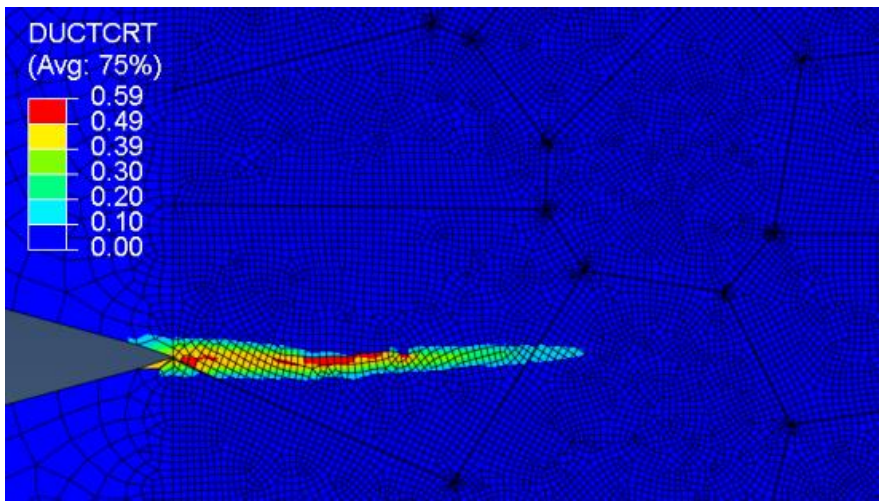

(d) 15 times higher plastic properties in GB

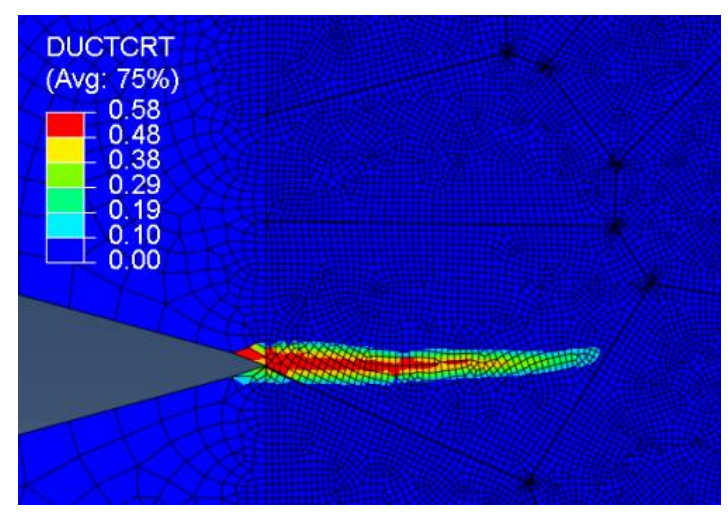

(c) 5 times higher plastic properties in GB
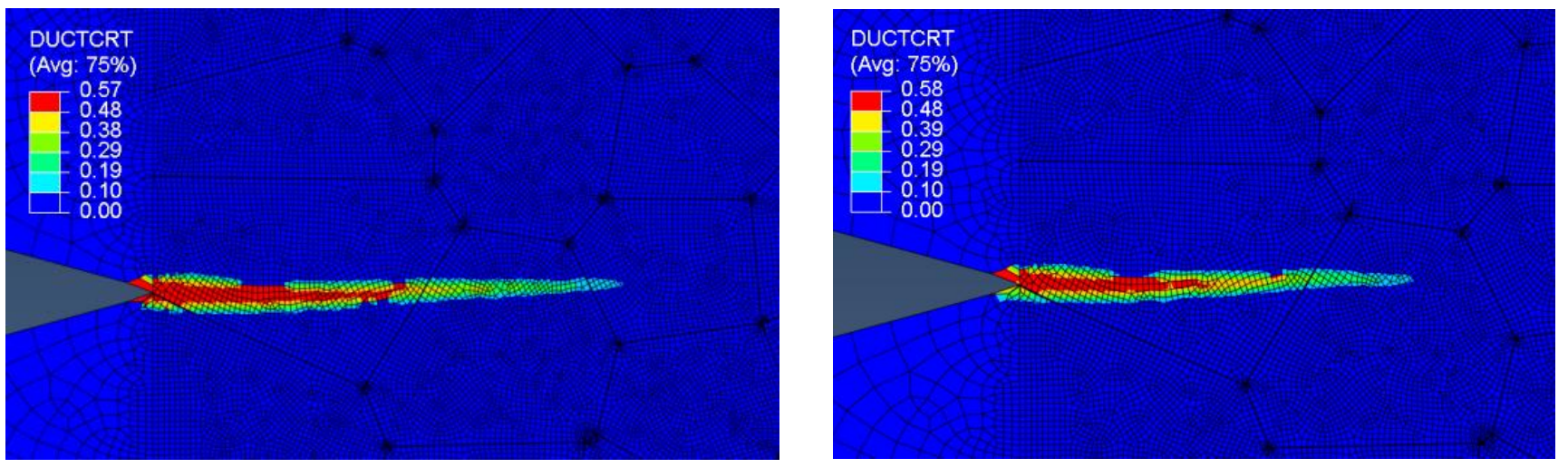

(e) 50 times higher plastic properties in GB

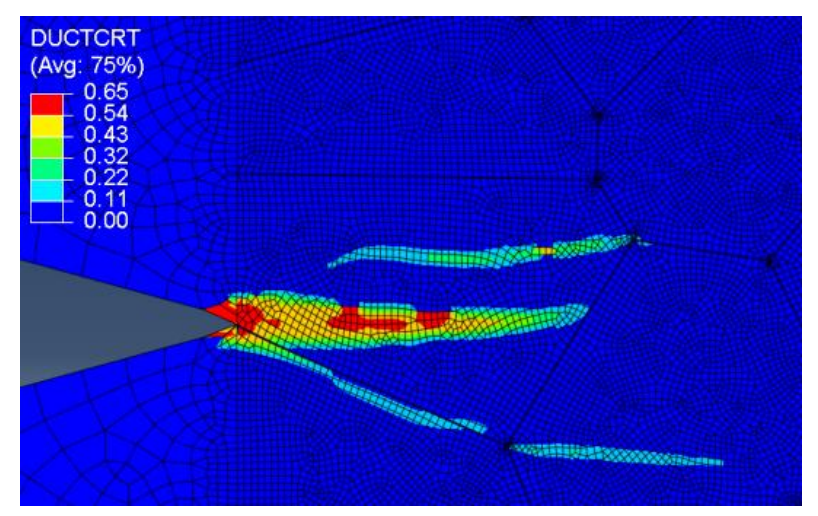

Figure 11: Damage path predictions for $0^{\circ}$ rotated unit cell using Case 2 material properties scenario 
(a) 1.1 times higher plastic properties in GB
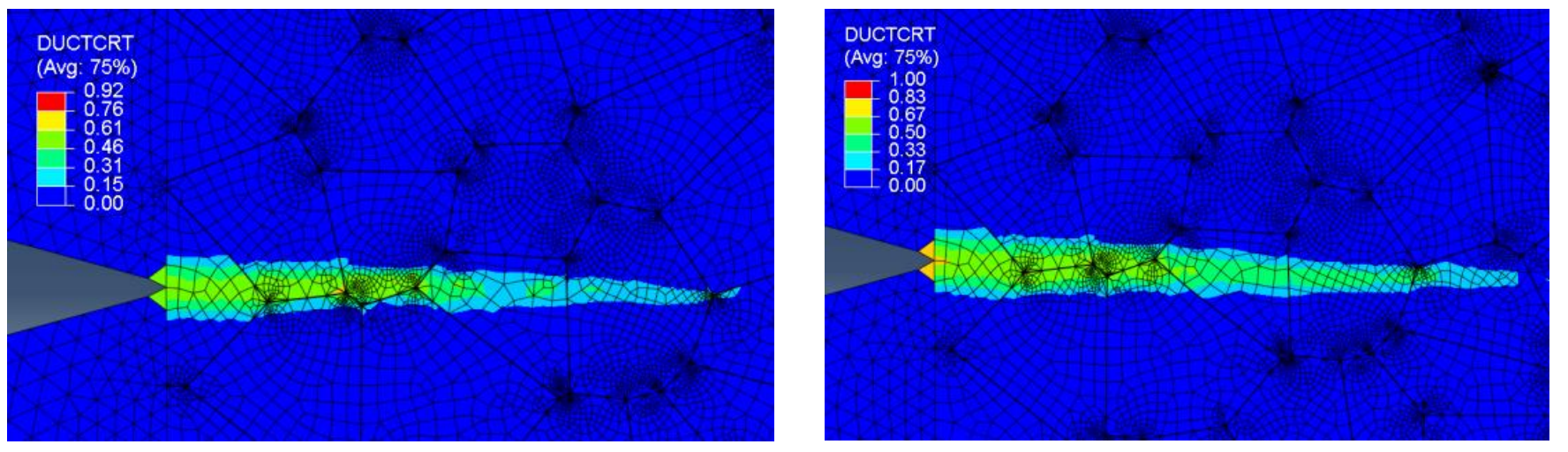

(d) 15 times higher plastic properties in GB

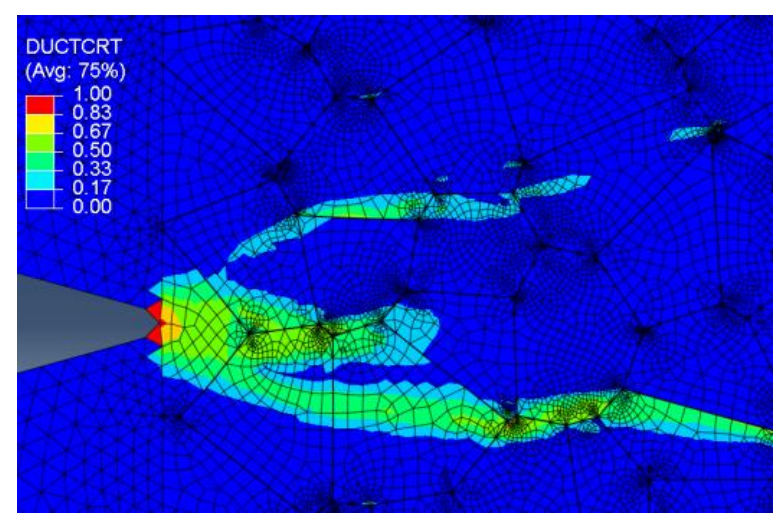

(e) 50 times higher plastic properties in GB

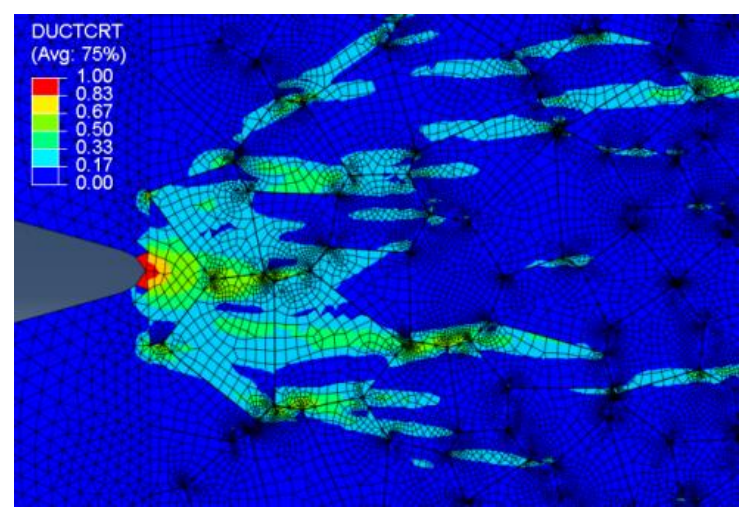

Figure 12: Damage path predictions for $90^{\circ}$ rotated unit cell using Case 2 material properties scenario 
(a) granular mesh at $0^{\circ}, 1.1$ times higher plastic properties in $\mathrm{GB}$

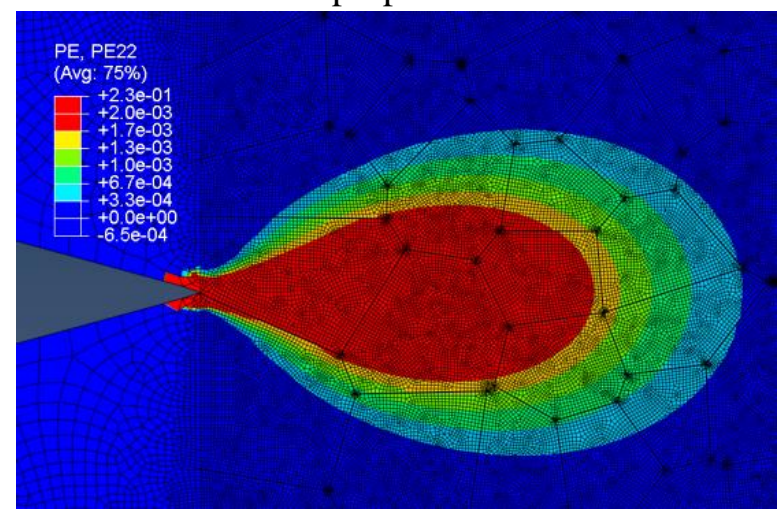

(d) granular mesh at $90^{\circ}, 1.1$ times higher plastic properties in GB

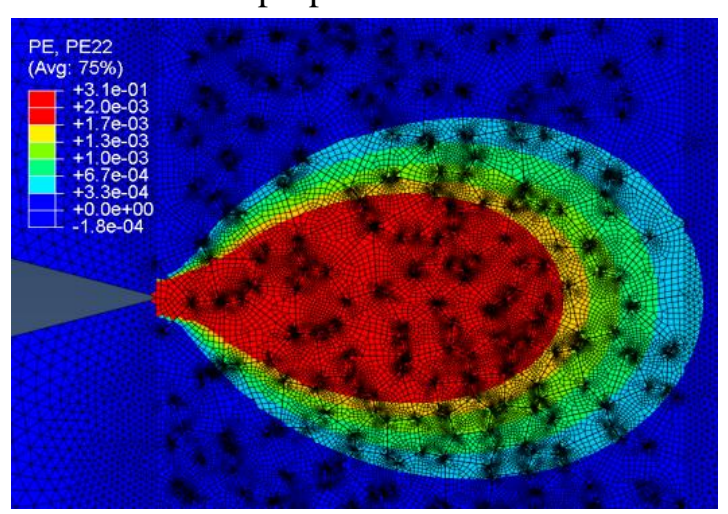

(b) granular mesh at $0^{\circ}, 5$ times higher plastic properties in GB

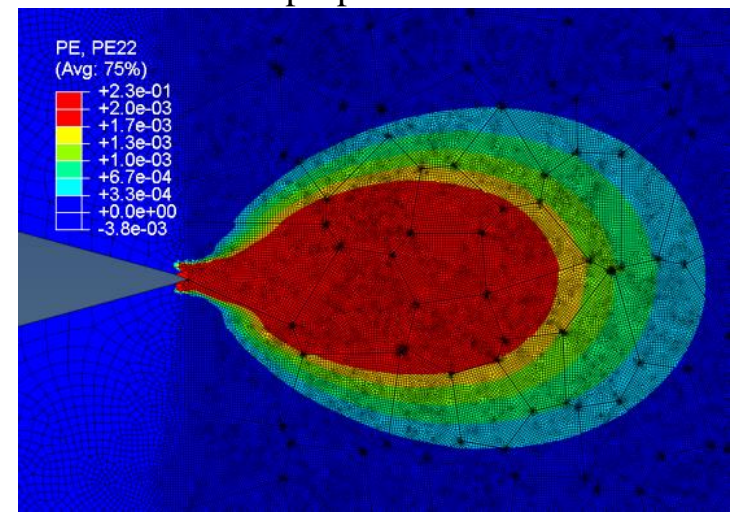

(e) granular mesh at $90^{\circ}, 5$ times higher plastic properties in GB

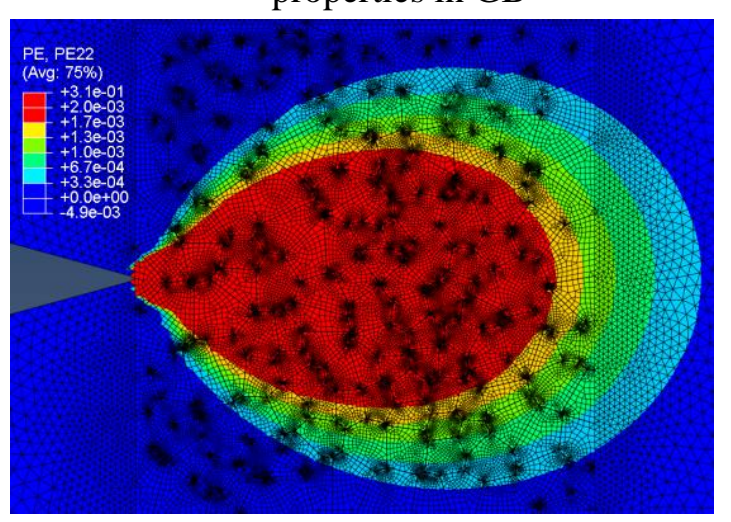

(c) granular mesh at $0^{\circ}, 15$ times higher plastic properties in GB

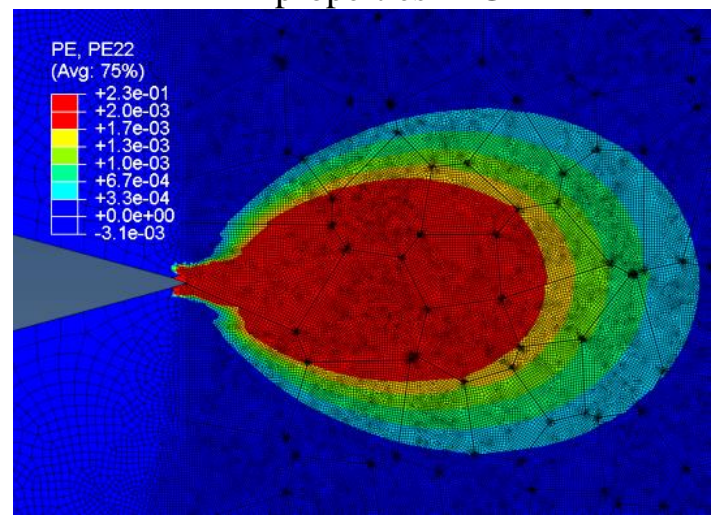

(f) granular mesh at $90^{\circ}, 15$ times higher plastic properties in GB

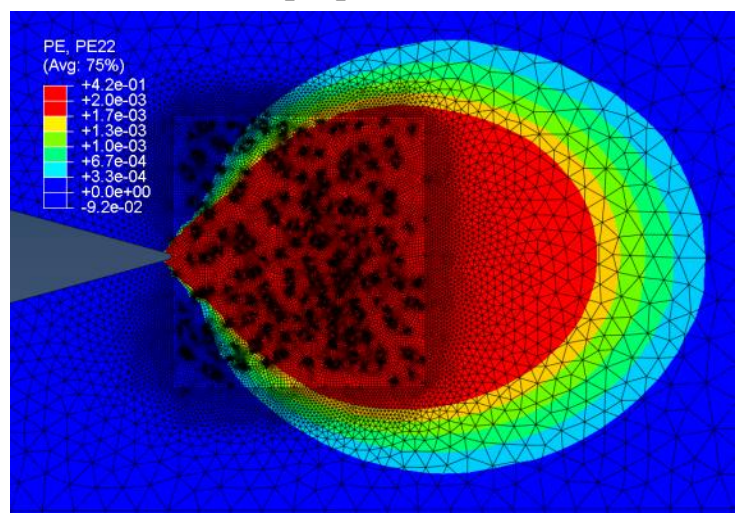

Figure 13: Plastic strain distribution fields predicted for Case 2 material properties scenario 


\subsection{Case 3 Material Properties Scenario}

In the Case 3 material properties scenario, elastic properties were assumed to be the same in grains and GBs (see Figure 1 and Table 1) and random plastic properties were assigned to various grains. Furthermore, higher but unified plastic properties were assigned to all the GBs in the FE models. In the first set of simulations, grain plastic properties were randomly selected from the scatter range of $\pm 6 \%$ of the mean plastic properties of the bulk material (see Table 1 and Figure 1) and GB plastic properties of 1.1, 1.5 and 100 times higher than the bulk properties were employed in the FE simulations. The predicted damage paths in simulations with the original granular unit cell (i.e. $0^{\circ}$ rotated unit cell) are shown in Figure 14(a)-(h). It can be seen in Figure 14(a) that when random plastic properties, within $\pm 6 \%$ of the mean yield stress, were assigned to various grains and the GBs had 1.1 times higher plastic properties, a transgranular crack path initiated at the crack tip and developed downwards with the deviation angle of $6^{\circ}$ from the specimen symmetry line. As seen in Figure 14(a) the damage path was then turned intergranular and deviated back towards the symmetry line. In order to examine the mesh size effects on the predicted crack path, this simulation was repeated with finer elements and the results are shown in Figure 14(b). As seen in this figure, the finer mesh led to a relatively straight transgranular crack path, though a discontinuous intergranular crack path with the same propagation direction as that observed in Figure 14(a) was predicted in the region further away from the crack tip. To examine the influence of random grain properties on the predicted damage path, the FE simulation on this granular unit cell with 1.1 higher GB plastic properties was repeated by assigning two new sets of random plastic properties to different grains and the results are shown in Figure 14(c) and Figure 14(d). Comparing Figure 14(a), Figure 14(c) and Figure 14(d) it can be seen that repeating the simulation on the same mesh but with new sets of random grain properties led to an intergranular damage initiation path with a downwards deviation angle of $25^{\circ}$ in the crack tip region. This damage was then turned transgranular with a gradual upwards deviation angle towards the specimen symmetry line. Also seen in Figure 14(d) is some evidence of an intergranular damage path on the GBs further down the main damage path, with an angle of close to $90^{\circ}$ to the loading direction.

To examine the influence of GB properties on crack path predictions, the FE simulation was performed on the same granular mesh structure using 1.5 times higher GB yield stress than the bulk plastic properties and the results are shown in Figure 14(e). Comparing Figure 14(a) and Figure 14(e) it can be seen that increasing the GB yield stress did not influence the predicted damage path. However, when new random properties within $\pm 6 \%$ mean plastic properties were assigned to various grains (see Figure 14(f)), a straight transgranular damage path was predicted ahead of the crack tip with a number of disjointed intergranular damage paths away from the crack tip, most of which have GB angles of close to $90^{\circ}$ to the loading direction. The GB plastic property effects were examined further by assigning GB properties of 100 times higher than the bulk material. Simulations were performed with two sets of random grain properties and the results are shown in Figure 14(g) and Figure 14(h). As seen in these two figures similar straight transgranular damage paths were predicted in both simulations, with a greater number of disjointed intergranular damage paths formed away from the crack tip in Figure 14(g) compared to Figure 14(h).

The influence of granular microstructure effects on the predicted damage paths for the Case 3 material properties scenario was investigated by performing simulations on the $90^{\circ}$ rotated granular unit cell. It can be seen in Figure 14(i) that when 1.1 times higher plastic properties were assigned to GB regions and random plastic properties of within $\pm 6 \%$ mean properties 
were assigned to various grains, a straight damage path was initiated in the crack tip region. This was followed by a discontinuous transgranular-intergranular damage path deviating away from the specimen symmetry line. This simulation was repeated by assigning 100 times higher plastic properties to GB regions and, as seen in Figure 14(j), a bigger transgranular damage path was predicted in the crack tip region with a greater number of disjointed intergranular damage paths forming away from the crack tip.

The plastic distribution fields corresponding to each of the damage path simulations in Figure 14 are shown in Figure 15. It can be seen in Figure 15(a)-(j) that when random plastic properties are assigned to various grains, non-homogeneous plastic strain fields with higher values close to the crack tip region (due to the stress concentration at the crack tip) are predicted in FE simulations. Comparison of the plastic distribution fields in Figure 15(a)-(j) with the corresponding damage path predictions in Figure 14(a)-(j) shows that damage path deviation at the crack tip and intergranular damage path formation away from the crack tip always occur in the high plastic strain regions in the granular mesh structure. This indicates that transgranular and intergranular damage paths ahead of the crack tip region occur around the grains with lower yield stress, which experience higher plastic strains and subsequently greater plastic damage. In other words, it can be observed in Figure 15 that the crack path deviation is controlled by individual grain properties and the grains with much lower yield stress, which are located in the region close to the crack tip, may lead to intergranular or transgranular crack paths. The maximum deviation angle observed in this study is $25^{\circ}$ with respect to the specimen symmetry line, though this value is highly subjective to the granular mesh structure employed in the analysis and may increase or decrease by using a different granular unit cell. 
(a) 1.1 times higher plastic properties in $\mathrm{GB}$,

$0^{\circ}$ Granular unit cell rotation

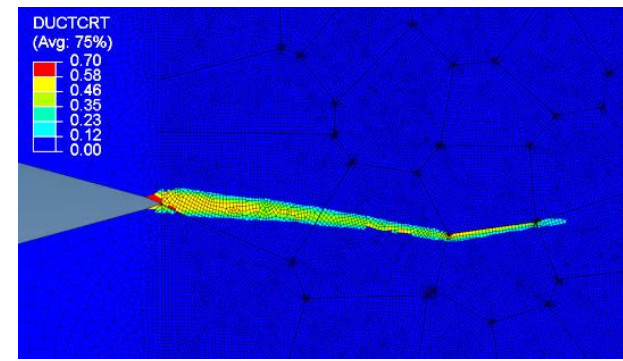

(e) 1.5 times higher plastic properties in GB, $0^{\circ}$ Granular unit cell rotation

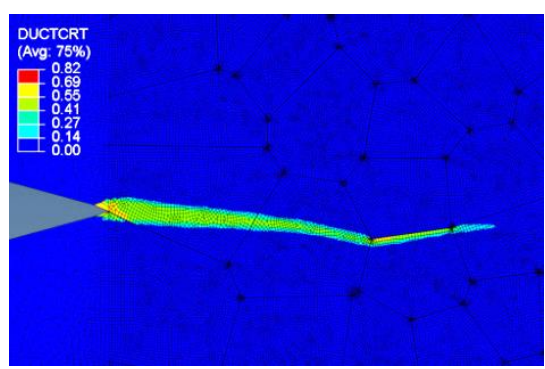

(h) 100 times higher plastic properties in GB, $0^{\circ}$ Granular unit cell rotation,

New random grain properties

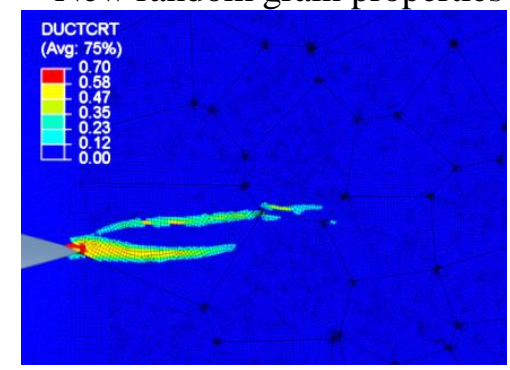

(b) 1.1 times higher plastic properties in GB,

$0^{\circ}$ Granular unit cell rotation with mesh refinement

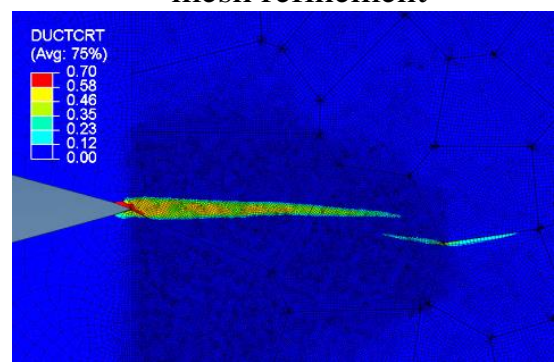

(f) 1.5 times higher plastic properties in GB, $0^{\circ}$ Granular unit cell rotation, New random grain properties

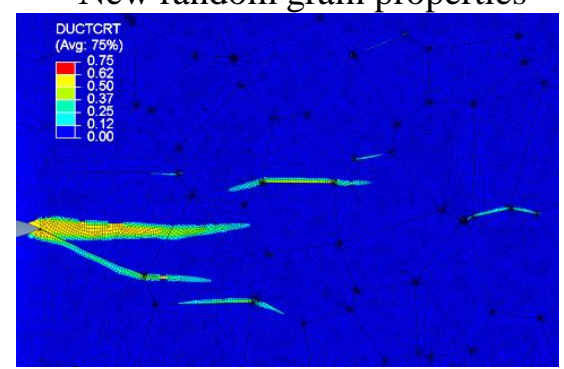

(i) 1.1 times higher plastic properties in GB, $90^{\circ}$ Granular unit cell rotation

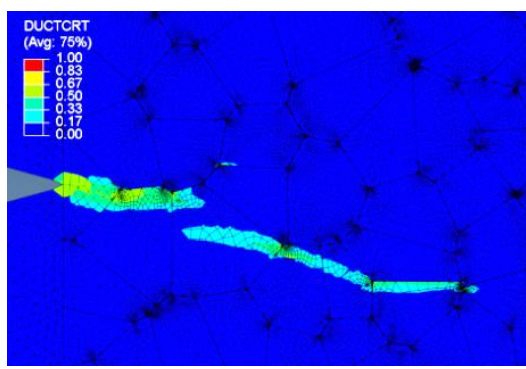

(d) 1.1 times higher plastic properties in $\mathrm{GB}$,

$0^{\circ}$ Granular unit cell rotation, New random grain properties

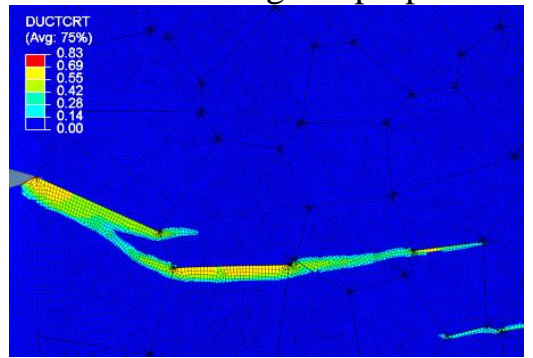

(g) 100 times higher plastic properties in GB, $0^{\circ}$ Granular unit cell rotation

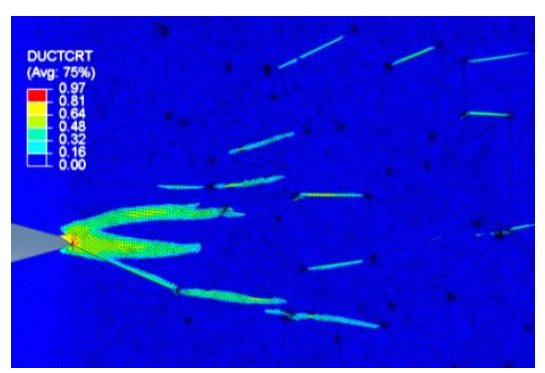

(j) 100 times higher plastic properties in GB, $90^{\circ}$ Granular unit cell rotation

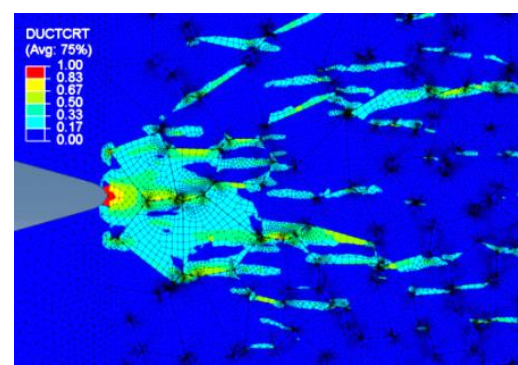

Figure 14: Damage path predictions for Case 3 material properties scenario with $\pm 6 \%$ variation in grain plastic properties 
(a) 1.1 times higher plastic properties in GB,

$0^{\circ}$ Granular unit cell rotation

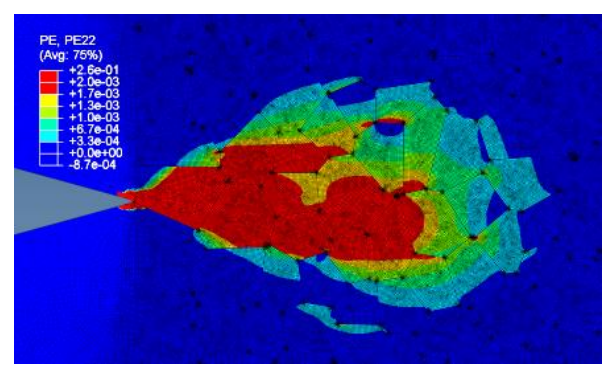

(e) 1.5 times higher plastic properties in GB, $0^{\circ}$ Granular unit cell rotation

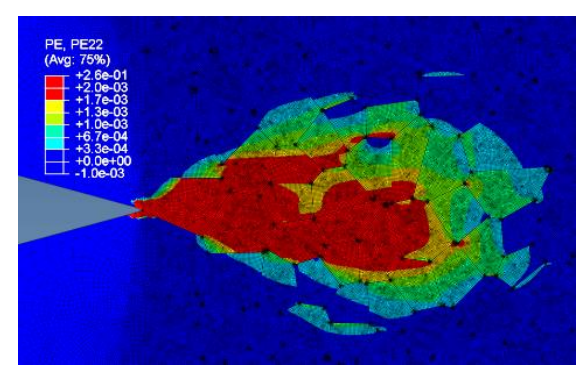

(h) 100 times higher plastic properties in GB, $0^{\circ}$ Granular unit cell rotation, New random grain properties

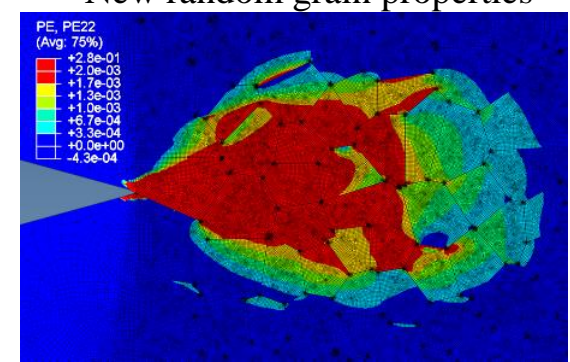

(b) 1.1 times higher plastic properties in GB,

$0^{\circ}$ Granular unit cell rotation with mesh refinement

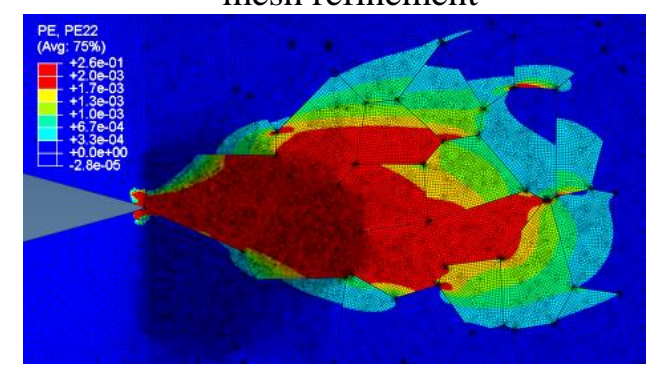

(f) 1.5 times higher plastic properties in GB, $0^{\circ}$ Granular unit cell rotation, New random grain properties

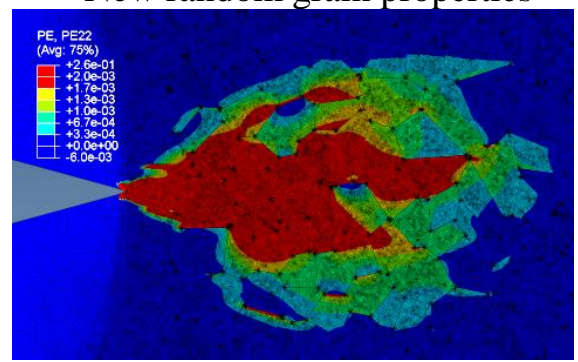

(i) 1.1 times higher plastic properties in GB, $90^{\circ}$ Granular unit cell rotation

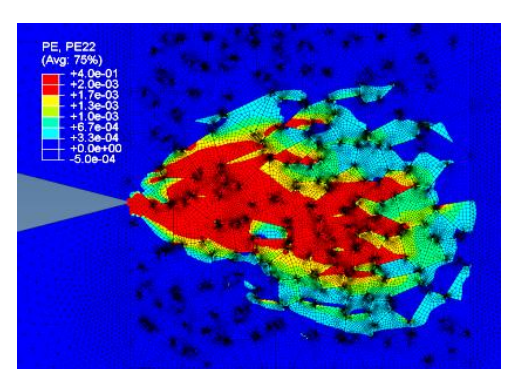

(d) 1.1 times higher plastic properties in GB,

$0^{\circ}$ Granular unit cell rotation, New random grain properties
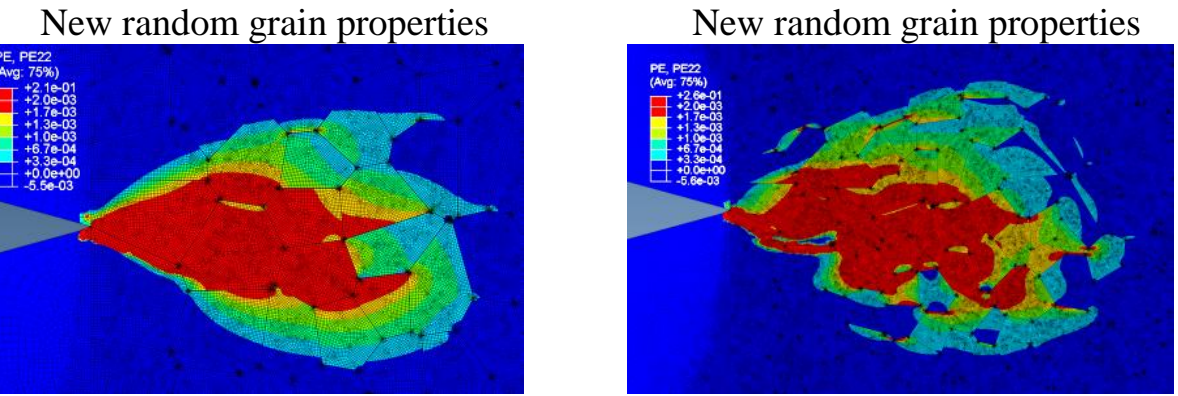

(g) 100 times higher plastic properties in GB, $0^{\circ}$ Granular unit cell rotation

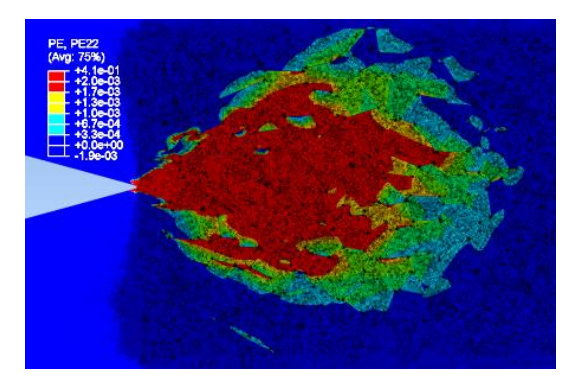

(j) 100 times higher plastic properties in GB, $90^{\circ}$ Granular unit cell rotation

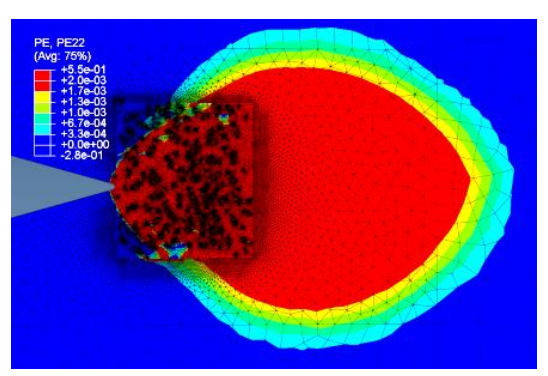

Figure 15: Plastic strain distribution fields predicted for Case 3 material properties scenario with $\pm 6 \%$ variation in grain plastic properties 20 
In order to investigate the effects of individual grain properties' diversity on the predicted damage paths, FE simulations on the original granular mesh structure (with $0^{\circ}$ unit cell rotation) were repeated by assigning GB plastic properties of 1.1 times higher than the mean properties and random plastic properties of $\pm 3 \%$ and $\pm 12 \%$ scatter range. The predicted damage path results from these simulations are shown in Figure 16 and Figure 17. Comparison of Figure 14(a), Figure 14(c) and Figure 14(d) (with $\pm 6 \%$ variation in grain plastic properties) with Figure 16 (with $\pm 3 \%$ variation in grain plastic properties) and Figure 17 (with $\pm 12 \%$ variation in grain plastic properties) reveals that under a given loading condition and damage criteria, the damage paths predicted by FE simulations are not repeatable. Moreover, the indicative crack paths may change by assigning new random plastic properties to various grains.

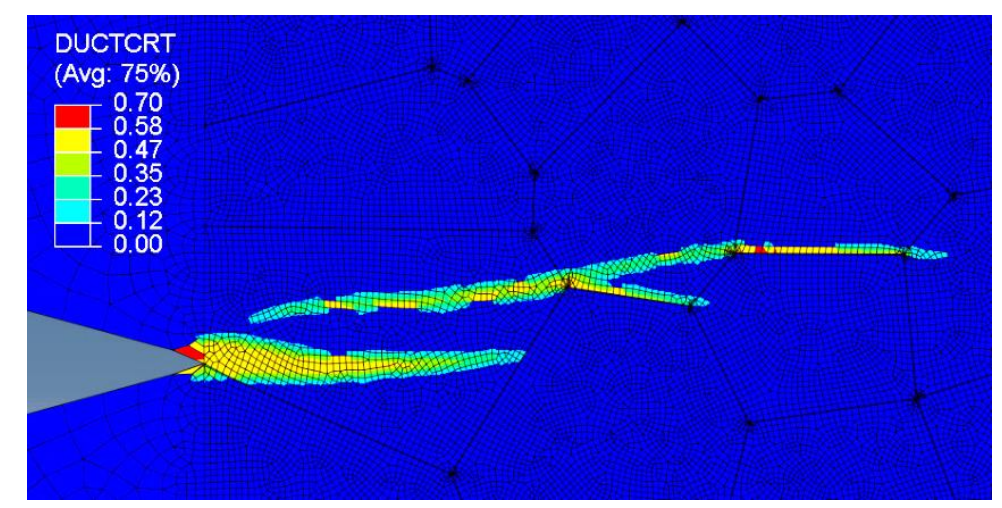

Figure 16: Damage path predictions for Case 3 material properties scenario with $\pm 3 \%$ variation in grain plastic properties

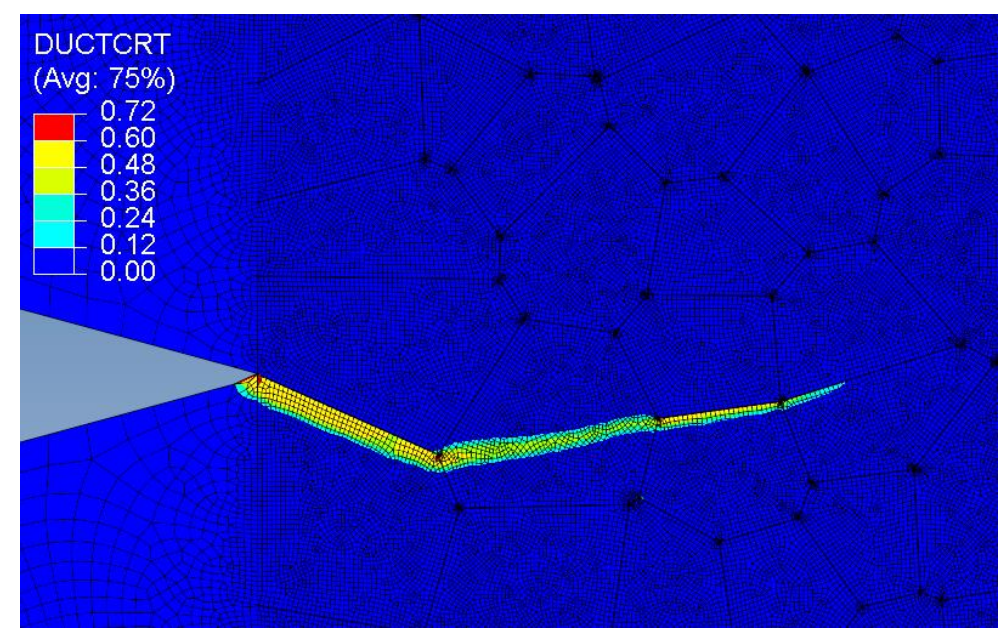

Figure 17: Damage path predictions for Case 3 material properties scenario with $\pm 12 \%$ variation in grain plastic properties 


\section{Discussion}

Mesoscale FE simulations on granular mesh structures have shown that the indicative crack propagation paths in polycrystalline materials subjected to monotonic loading conditions are sensitive to the granular microstructure, GB properties and individual grain properties. Simulation results shown in Figure 9 have revealed that when homogeneous elastic-plastic material properties are assigned to various grains and GB regions, the damage path and cracking mode is very sensitive to the shape of the grains populated within the granular mesh structure. It can be seen in Figure 9 that under the same loading conditions and damage criteria, the plastic damage paths can be transgranular or intergranular, depending on the material microstructure employed in the analysis. Furthermore, although the macroscopic damage paths in these simulations generally fall along the specimen symmetry line and normal to the maximum principal stress direction (i.e. parallel to the loading axis), the indicative crack path may deviate above and below the symmetry line in a mesoscale analysis.

Comparison of Figure 9 and Figure 11 shows the material property mismatch between grains and GBs can potentially change the damage development and subsequently crack propagation behaviour of the examined polycrystalline material. It can be observed in Figure 9 that when homogeneous properties were assigned to all the grains and GBs in the granular mesh structure, a continuous intergranular or transgranular damage path was predicted in FE simulations. However, the nano-indentation test results in Figure 3 and Figure 4 suggest that the hardness, hence yield stress, is higher in the GB regions compared to the grains. Therefore, higher yield stress was assigned to the family of GBs in the model (see Case 2 in Section 3.2) and it was seen that in addition to the main damage path, other disjointed intergranular or transgranular damage paths are formed further away from the crack tip. Note that for simplicity, in this work the criteria for damage initiation and evolution were assumed to be the same for grain and GB elements. However, distinct damage criteria (for instance transgranular fatigue damage and intergranular creep damage) for grains and GBs will be employed in future work to examine the crack growth behaviour of the material under creep-fatigue loading conditions.

Simulation results on granular mesh structures with different plastic properties for various grains and higher GB yield stress in Figure 14(a), Figure 14(b), Figure 14(c), Figure 16 and Figure 17 have shown that the properties of individual grains may have a significant influence of the main damage path direction and deviation angle in FE predictions. The plastic distribution fields for the corresponding crack path simulations have revealed that the main damage path is more likely to develop through the grains with lower yield stress (hence greater plastic strain) located close to the crack tip. This observation is consistent with that reported in [39] in which the analysis has shown that the crack may prefer to propagate through the soft, rather than hard grains, and choose to growth through the slip plane that is more perpendicular to the external load.

It is also apparent in the damage path prediction results that the material mismatch between individual grains and also GBs may lead to crack branching in some of the FE analyses. Similar experimental observations of crack bifurcation occurring at high crack tip velocities have been reported by other researchers such as the study of short term (i.e. high load) creep crack growth behaviour in $316 \mathrm{H}$ at $550{ }^{\circ} \mathrm{C}$ in [16]. 
Another interesting observation which can be made by comparing the damage path predictions in Figure 14(e)-(j) is that the intergranular damage path density seen in those GBs which have angles of close to $90^{\circ}$ to the maximum principal stress direction and are located away from the main damage path, is sensitive to the GB properties. These figures suggest that by increasing the yield stress in the GB elements, the number of disjointed intergranular microcracks predicted in FE simulations significantly increases. This effect is more pronounced when the GB yield stress is much higher (for instance 100 times greater) than the bulk properties.

Finally, comparison of the damage path prediction results in Figure 14 shows that the mesoscale transgranular/intergranular cracking mode and the deviation angle is strongly dependent on the granular mesh structure employed in the FE analysis and the material properties assigned to individual grains and GBs. The simulation results in Figure 14 have exhibited that the maximum deviation angle obtained from this study is $25^{\circ}$ with respect to the specimen symmetry line, though it must be noted that this deviation angle was observed when intergranular damage paths were predicted at the crack tip. This implies that the maximum deviation angle was dictated by the GB, hence is strongly dependent on the granular microstructure employed in the analysis.

The FE simulations in this study were performed on 2D granular mesh structures under plane stress conditions. This means that although the indicative crack discontinuities were predicted by FE simulations in the current work, if the simulations were repeated on a 3D granular mesh structure the disjointed cracks predicted at different planes could have linked up to form a continuous crack propagation path throughout the specimen. Note that even for the 2D granular mesh structures employed in the present study, a large number of elements (around 1 million) were used to mesh the structure. This required a considerable computational power to complete FE simulations with damage calculations. Therefore, although 3D crack propagation simulations may provide more information about the coalescence of discontinuous cracks at different planes, attention must be paid to the fact that 3D simulations will need an extremely greater number of elements and therefore a significantly longer computation time to complete FE simulations.

\section{Conclusions}

The sensitivity of crack paths to the granular microstructure has been numerically analysed for a polycrystalline material $(316 \mathrm{H}$ stainless steel) using a mesoscale $\mathrm{FE}$ modelling approach. The FE results have shown that under tensile loading conditions, the indicative crack paths are sensitive to the material properties assigned to individual grains and GBs, along with the shape and size of the grains employed in the model. The numerical results obtained from a range of granular mesh structures examined in this study have revealed that the material microstructure may lead to damage path deviations of up to $25^{\circ}$ from the symmetry line. The results have also shown that the maximum deviation angle was dictated by the GB angle located at the crack tip, suggesting that the maximum deviation angle strongly depends on the granular microstructure employed in the analysis. Moreover, it has been observed in the FE simulation results that the damage paths ahead of the crack tip are sensitive to individual grain properties and may deviate towards those grains with lower yield stress (hence greater plastic damage). The simulation results have also shown that by increasing the yield stress in the GB regions, 
the number of disjointed intergranular damage paths along those GBs with angles of close to $90^{\circ}$, with respect to the loading direction, increases in the regions away from the main indicative crack path.

\section{REFERENCES}

[1] C. M. Davies, N. P. O'Dowd, K. M. Nikbin, and G. A. Webster, “An analytical and computational study of crack initiation under transient creep conditions," Int. J. Solids Struct., vol. 44, no. 6, pp. 1823-1843, 2007.

[2] A. Mehmanparast, C. M. Davies, G. A. Webster, and K. M. Nikbin, "Creep crack growth rate predictions in $316 \mathrm{H}$ steel using stress dependent creep ductility," Mater. High Temp., vol. 31, no. 1, pp. 84-94, 2014.

[3] N. Gupta and P. Pachauri, "An Experimental and Computational Investigation of Crack Growth Initiation in Compact Tension (CT) Specimen," Ijsrp.Org, vol. 2, no. 8, pp. 1-7, 2012.

[4] D. Xie and A. M. Waas, "Discrete cohesive zone model for mixed-mode fracture using finite element analysis," Eng. Fract. Mech., vol. 73, no. 13, pp. 1783-1796, 2006.

[5] N. Moës and T. Belytschko, "Extended finite element method for cohesive crack growth," Eng. Fract. Mech., vol. 69, no. 7, pp. 813-833, 2002.

[6] J. Shi, D. Chopp, J. Lua, N. Sukumar, and T. Belytschko, “Abaqus implementation of extended finite element method using a level set representation for three-dimensional fatigue crack growth and life predictions," Eng. Fract. Mech., vol. 77, no. 14, pp. 2840-2863, 2010.

[7] I. V. Singh, B. K. Mishra, S. Bhattacharya, and R. U. Patil, "The numerical simulation of fatigue crack growth using extended finite element method," Int. J. Fatigue, vol. 36, no. 1, pp. 109-119, 2012.

[8] N. Sukumar, N. Moës, B. Moran, and T. Belytschko, "Extended finite element method for three-dimensional crack modelling," Int. J. Numer. Methods Eng., vol. 48, no. 11, pp. 1549-1570, 2000.

[9] E. Giner, N. Sukumar, J. E. Tarancón, and F. J. Fuenmayor, “An Abaqus implementation of the extended finite element method," Eng. Fract. Mech., vol. 76, no. 3, pp. 347-368, 2009.

[10] A. R. Khoei, "Extended Finite Element Method: Theory and Applications," no. 1988, pp. 1-29, 2015. 
[11] G. K. Sfantos and M. H. Aliabadi, "A boundary cohesive grain element formulation for modelling intergranular microfracture in polycrystalline brittle materials," Int. J. Numer. Methods Eng., vol. 69, no. 8, pp. 1590-1626, 2007.

[12] T. Slack and F. Sadeghi, "Cohesive zone modeling of intergranular fatigue damage in rolling contacts," Tribol. Int., vol. 44, no. 7-8, pp. 797-804, 2011.

[13] T. Luther and C. Könke, "Polycrystal models for the analysis of intergranular crack growth in metallic materials," Eng. Fract. Mech., vol. 76, no. 15, pp. 23322343, 2009.

[14] F. Roters, P. Eisenlohr, L. Hantcherli, D. D. Tjahjanto, T. R. Bieler, and D. Raabe, "Overview of constitutive laws, kinematics, homogenization and multiscale methods in crystal plasticity finite-element modeling: Theory, experiments, applications," Acta Mater., vol. 58, no. 4, pp. 1152-1211, 2010.

[15] D. Raabe and F. Roters, "Using texture components in crystal plasticity finite element simulations," Int. J. Plast., vol. 20, no. 3, pp. 339-361, 2004.

[16] D. W. Dean and D. N. Gladwin, "Creep crack growth behaviour of Type 316H steels and proposed modifications to standard testing and analysis methods," Int. J. Press. Vessel. Pip., vol. 84, no. 6, pp. 378-395, 2007.

[17] P. Onck and E. van der Giessen, "Micromechanics of creep fracture: simulation of intergranular crack growth," Comput. Mater. Sci., vol. 13, no. 1-3, pp. 90$102,1998$.

[18] S. Xu, X. Wu, A. Koul, and J. Dickson, "An intergranular creep crack growth model based on grain boundary sliding," Metall. Mater. Trans. A, vol. 30, no. 4, pp. 1039-1045, 1999.

[19] K. Sadananda and A. K. Vasudevan, "Fatigue crack growth mechanisms in steels," Int. J. Fatigue, vol. 25, no. 9-11, pp. 899-914, 2003.

[20] K. S. Chan, "A microstructure-based fatigue-crack-initiation model," Metall. Mater. Trans. A, vol. 34, no. 1, pp. 43-58, 2003.

[21] A. Mehmanparast, F. R. Biglari, C. M. Davies, and K. M. Nikbin, “An Investigation of Irregular Crack Path Effects on Fracture Mechanics Parameters Using a Grain Microstructure Meshing Technique," J. Multiscale Model., vol. 04, no. 01, p. 1250001, 2012.

[22] A. Mehmanparast and K. Nikbin, "The importance of micro-crack evolution under oxidation / creep conditions in component failure life predictions," pp. 1-4. 
[23] F. Biglari and K. M. Nikbin, "Environmental creep intergranular damage and multisite crack evolution model for engineering alloys," Comput. Mater. Sci., vol. 84, pp. 267-277, 2014.

[24] A. Mehmanparast, C. M. Davies, D. W. Dean, and K. M. Nikbin, "The influence of pre-compression on the creep deformation and failure behaviour of Type $316 \mathrm{H}$ stainless steel," Eng. Fract. Mech., vol. 110, pp. 52-67, 2013.

[25] A. Mehmanparast, C. M. Davies, D. W. Dean, and K. Nikbin, "Material preconditioning effects on the creep behaviour of $316 \mathrm{H}$ stainless steel," Int. J. Press. Vessel. Pip., vol. 108-109, pp. 88-93, 2013.

[26] A. Mehmanparast, C. M. Davies, D. W. Dean, and K. M. Nikbin, "Plastic precompression and creep damage effects on the fracture toughness behaviour of Type 316H stainless steel," Eng. Fract. Mech., vol. 131, no. 0, pp. 26-37, 2014.

[27] D.-F. Li, C. M. Davies, S.-Y. Zhang, C. Dickinson, and N. P. O’Dowd, "The effect of prior deformation on subsequent microplasticity and damage evolution in an austenitic stainless steel at elevated temperature," Acta Mater., vol. 61, no. 10, pp. 3575-3584, 2013.

[28] D. F. Li, N. P. O’Dowd, C. M. Davies, and S. Y. Zhang, "Microscale prediction of deformation in an austenitic stainless steel under uniaxial loading," Eur. J. Mech. A/Solids, vol. 30, no. 5, pp. 748-760, 2011.

[29] C. M. Davies, A. Mehmanparast, and S. Zhang, "Plastic Pre-Strain Effects on the Intergranular Strains in 316H Stainless Steel.," in 7th International Conference on Mechanical Stress Evaluation by Neutrons and Synchrotron Radiation (MECA SENS VII 2013), Sydney, Australia., 2013.

[30] J. Morris, "The influence of grain size on the mechanical properties of steel," Lawrence Berkeley Natl. Lab., pp. 34-41, 2001.

[31] C.-H. Qin, X.-C. Zhang, S. Ye, and S.-T. Tu, "Grain size effect on multi-scale fatigue crack growth mechanism of Nickel-based alloy GH4169," Eng. Fract. Mech., vol. 142, pp. 140-153, 2015.

[32] A. Mehmanparast, C. M. Davies, M. Ardakani, and K. M. Nikbin, "A Microstructural Study of Compressive Plastic Pre-Strain Effects on Creep Damage Behaviour of Type 316H Stainless Steel.," in ASME-PVP Conference, Baltimore, US, 2011.

[33] P. Zhang, M. Karimpour, D. Balint, J. Lin, and D. Farrugia, “A controlled Poisson Voronoi tessellation for grain and cohesive boundary generation applied to crystal plasticity analysis," Comput. Mater. Sci., vol. 64, pp. 84-89, 2012. 
[34] J. Dzugan, M. Spaniel, P. Konopík, J. Ruzicka, and J. Kuzelka, "Identification of Ductile Damage Parameters for Austenitic Steel," pp. 1297-1302, 2012.

[35] J. Lemaitre, "A continuous damage mechanics model for ductile fracture," $J$. Eng. Mater. Technol. Trans. ASME, vol. 107, no. January 1985, pp. 83-89, 1985.

[36] J. Lemaitre, "How to use damage mechanics," Nucl. Eng. Des., vol. 80, no. 2, pp. 233-245, 1984.

[37] J. L. Chaboche, "Continuum Damage Mechanics: Part II - Damage Growth, Crack Initiation, and Crack Growth," J. Appl. Mech., vol. 55, no. March 1988, pp. 65-72, 1988.

[38] S. Murakami, Solid Mechanics and Its Applications- Continuum Damage Mechanics. Springer, 2012.

[39] I. Simonovski, K. F. Nilsson, and L. Cizelj, "The influence of crystallographic orientation on crack tip displacements of microstructurally small, kinked crack crossing the grain boundary," Comput. Mater. Sci., vol. 39, no. 4, pp. 817-828, 2007. 